OPEN ACCESS

Edited by:

Richard P. Tucker,

University of California, Davis,

United States

Reviewed by:

Jong-lk Hwang,

Korea University, South Korea

Wei-jiang Zhao

Shantou University Medical College,

China

*Correspondence:

Annemarie Ziegler aziegler@udd.c

Specialty section:

This article was submitted to Neuroendocrine Science,

a section of the journal

Frontiers in Neuroscience

Received: 28 September 2018 Accepted: 28 November 2018 Published: 11 December 2018

Citation:

Rebolledo-Jaramillo B and Ziegler A (2018) Teneurins: An Integrative Molecular, Functional, and Biomedical

Overview of Their Role in Cancer. Front. Neurosci. 12:937. doi: 10.3389/fnins.2018.00937

\section{Teneurins: An Integrative Molecular, Functional, and Biomedical Overview of Their Role in Cancer}

\author{
Boris Rebolledo-Jaramillo and Annemarie Ziegler* \\ Center for Genetics and Genomics, Facultad de Medicina, Clínica Alemana Universidad del Desarrollo, Santiago, Chile
}

Teneurins are large transmembrane proteins originally identified in Drosophila. Their essential role in development of the central nervous system is conserved throughout species, and evidence supports their involvement in organogenesis of additional tissues. Homophilic and heterophilic interactions between Teneurin paralogues mediate cellular adhesion in crucial processes such as neuronal pathfinding and synaptic organization. At the molecular level, Teneurins are proteolytically processed into distinct subdomains that have been implicated in extracellular and intracellular signaling, and in transcriptional regulation. Phylogenetic studies have shown a high degree of intra- and interspecies conservation of Teneurin genes. Accordingly, the occurrence of genetic variants has been associated with functional and phenotypic alterations in experimental systems, and with some inherited or sporadic conditions. Recently, tumor-related variations in Teneurin gene expression have been associated with patient survival in different cancers. Although these findings were incidental and molecular mechanisms were not addressed, they suggested a potential utility of Teneurin transcript levels as biomarkers for disease prognosis. Mutations and chromosomal alterations affecting Teneurin genes have been found occasionally in tumors, but literature remains scarce. The analysis of open-access molecular and clinical datasets derived from large oncologic cohorts provides an invaluable resource for the identification of additional somatic mutations. However, Teneurin variants have not been classified in terms of pathogenic risk and their phenotypic impact remains unknown. On this basis, is it plausible to hypothesize that Teneurins play a role in carcinogenesis? Does current evidence support a tumor suppressive or rather oncogenic function for these proteins? Here, we comprehensively discuss available literature with integration of molecular evidence retrieved from open-access databases. We show that Teneurins undergo somatic changes comparable to those of well-established cancer genes, and discuss their involvement in cancer-related signaling pathways. Current data strongly suggest a functional contribution of Teneurins to human carcinogenesis.

Keywords: Teneurin/ODZ, somatic aberrations, cancer signaling pathways, data mining, tumorigenesis 


\section{INTRODUCTION}

Teneurins compose a family of large transmembrane proteins identified over two decades ago in Drosophila (Baumgartner et al., 1994; Levine et al., 1994). Their high degree of interspecies conservation was evidenced through early phylogenetic analyses, and in the human genome, four highly related gene paralogues (TENM1 through TENM4) were predicted based on DNA sequence homologies and partial expression data (Minet and Chiquet-Ehrismann, 2000; Tucker et al., 2012). In vertebrates as in other species, expression of Teneurins has consistently been allocated to the developing nervous system, where they guide formation of neuronal networks through homophilic and heterophilic interactions across synaptic spaces (Hong et al., 2012; Beckmann et al., 2013; Boucard et al., 2014; Berns et al., 2018). Avian and invertebrate Teneurins have further been related to the development of non-neural tissues including the gonads, heart, pharynx, limbs and the gut, among others (Tucker et al., 2001; Drabikowski et al., 2005; Trzebiatowska et al., 2008). In terms of gene organization, Teneurins have shown to be large and complex, displaying multiple alternatively spliced forms in all species analyzed (Tucker et al., 2001, 2012; Lossie et al., 2005; Berns et al., 2018). Accordingly, Teneurin functional analysis is not straightforward and requires experimental consideration of multiple protein subspecies, which might present distinct spatial and temporal expression patterns during development. This inherent complexity challenges the study of newly discovered Teneurin structural and genetic variants. However, the prominent technological and bioinformatics development, together with the ease of access to molecular information gathered into large cancer databases, facilitates oncology research, and can be applied to understanding the significance of Teneurins in carcinogenesis. To this end, the current review integrates tumor-derived genomic and transcriptomic data available through the literature and open-access repositories. The main subjects have been organized according to the historic timeline of their appearance, with the goal to construct a role of Teneurins in cancer starting form a structural point of view into the function and biomedical associations. Based on current knowledge, we propose a plausible role for Teneurins in tumor cell signaling and as recurrent targets of somatic alterations. The function of Teneurins in neural development will not be explicitly addressed, as it will be discussed in detail in other contributions within the current issue.

\section{TENEURIN GENES: TARGETS FOR STRUCTURAL ALTERATIONS IN CELL LINES AND TUMORS}

\section{Chromosomal Rearrangements in Reports and Data Repositories}

Since their discovery over two decades ago, Teneurin research has predominantly addressed their importance as morphogens and determinants of neural connectivity during embryonal development. Intrinsically, this has determined the use of suitable animal models such as C. elegans, Drosophila, chicken and mice, that allowed functional and structural characterization of Teneurins and analysis of gene expression patterns (Baumgartner et al., 1994; Oohashi et al., 1999; Rubin et al., 1999; Fascetti and Baumgartner, 2002; Drabikowski et al., 2005). Conversely, studies assessing the role of human Teneurins were less frequent and their corresponding gene organization was largely predicted through homology-based sequence alignments and partial cloning strategies (Minet et al., 1999; Ben-Zur et al., 2000; Beckmann et al., 2011; Tucker et al., 2012). Discoveries comprising the human orthologs have thus been belated. This includes the identification of tumor-associated somatic changes involving the Teneurins, which has occurred incidentally and is less evident in the literature. In this context, one of the first traceable publications described a chromosomal translocation involving the TENM4 and NRG1 (Neuregulin-1) genes in a breast cancer cell line (Liu et al., 1999; Wang et al., 1999). Importantly, this rearrangement generated a biologically active fusion protein $(\gamma$-heregulin) that acted as a secreted autocrine and paracrine growth factor for MDA-MB-175 and MCF-7 breast cancer cells, respectively (Schaefer et al., 1997). Some 10 years later, a second report described recurrent translocations affecting the IGH (Immunoglobulin Heavy Locus) and TENM2 genes in mucosa associated lymphoid tissue (MALT) lymphomas of the skin and the ocular adnexa (Vinatzer et al., 2008). This seems consistent with the role of Teneurin-2 in development of binocular circuits in the visual system (Rubin et al., 2002; Young et al., 2013), while the C. elegans ortholog (Ten-1) is essential for hypodermal development (Mörck et al., 2010). A third translocation involving C11orf73 (current gene name is HIKESHI) and TENM1 was detected in an advanced B3 thymoma (Petrini et al., 2013).

Although scarce, the above findings pose the question whether rearrangement of Teneurin genes is a frequent and biologically relevant event in tumorigenesis. The advent of large, open-access data repositories gathering cancer-related data from thousands of patients, can now partly overcome the lack of explicit reports. Upon a search for chromosomal alterations in two curated sites (ChimerDB 3.0, http://203.255. 191.229:8080/chimerdbv31/mindex.cdb, and "Atlas of Genetics and Cytogenetics in Oncology and Hematology", http:// atlasgeneticsoncology.org/) (Huret et al., 2013; Lee et al., 2017), we were able to retrieve additional chromosomal rearrangements involving the TENM1, TENM2, and particularly TENM4 genes (Table 1). Some preliminary observations can be drawn from this overview. First, most reported translocations are derived from a few large and rather recent studies. Earlier data not submitted to a repository might have been missed, as exemplified by the IGH/TENM2 and C11orf73/TENM1 translocations in MALT and B3 thymoma, respectively. The frequency of Teneurin rearrangements might thus be underrepresented. Second, most translocations occur with distinct fusion partners and as unique events, both within each tumor type and among different tumors. Third, rearrangements involving TENM4 clearly predominate (24/32, 75\%), followed by TENM2 (5/32, 15.6\%) and TENM1 $(3 / 32,9.4 \%)$. No translocations have apparently been reported for TENM3. Finally, 18/32 (56\%) of translocations occurred in breast cancer, and most were intrachromosomal (22/32, 69\%). 
TABLE 1 | Reported tumor cytogenetic rearrangements involving Teneurin genes.

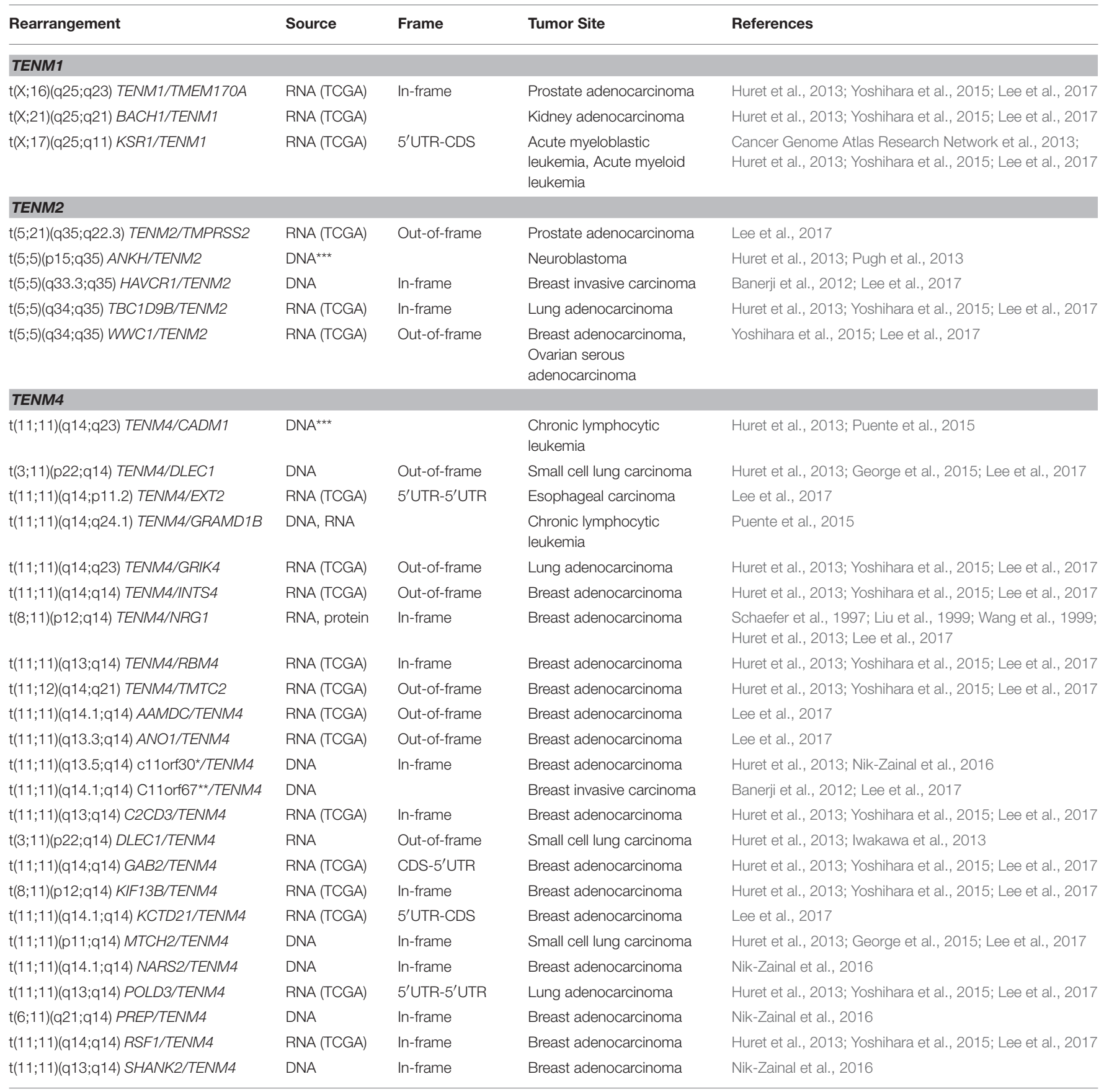

"C110rf30 current consensus gene name is EMSY; ** 11 orf67 current consensus gene name is AAMDC; ${ }^{* \star *}$ present in DNA only, no expression of fusion transcript. Only rearrangements with information on tumor origin were included.

\section{Mechanistic Base For Chromosomal Alterations}

Under the assumption that all Teneurin genes had comparable sequence coverage in the above genome-wide approaches, these data would suggest preferential chromosome breakage at the TENM4 locus. The presence of common or rare fragile sites, as defined by their susceptibility to form gaps and breaks in metaphase chromosomes exposed to replicative stress, has been associated with structural DNA variation, including chromosomal rearrangements, and genomic instability in cancer (Glover et al., 2017). No explicit fragile sites encompassing Teneurin genes have been described in the literature, which is consistent with the lack of findings when we performed Teneurin gene-based searches of a database covering 
118 reported fragile sites in human chromosomes HumCFS, http://webs.iiitd.edu.in/raghava/humcfs/, (Kumar et al., 2017). However, an alternative mechanism proposed that transcription of large genes is associated with both copy number variation (CNV) and the formation of common fragile sites in the genome, through unrepaired lesions derived from failure at the replication fork (Smith et al., 2006; Wilson et al., 2015). Further, differential isoform expression of large genes has been associated with CNVs and common fragile sites that were cell-line specific. Based on this, we might predict that rearrangement of Teneurins could occur in a cell type-specific pattern, depending on the intrinsic transcriptional activity of each Teneurin gene and/or isoform expression in a particular tissue. This seems consistent with our previous detection of Teneurin- 4 and Teneurin-2 expression in ovarian tumors and breast cancer cell lines (Graumann et al., 2017), as both genes were preferentially targeted by rearrangements in breast tumors and in one ovarian cancer sample (Table 1). Conversely, structural alterations encompassing other Teneurins might be expected in tumors less represented in current databases, such as those affecting the nervous system where Teneurin-3 expression could be more prevalent. In fact, structural alterations of TENM3, including one case of homozygous inactivation, occurred in 5/87 pediatric neuroblastomas and were thus considered recurrent events (Molenaar et al., 2012). The same study detected an interchromosomal rearrangement involving CSMD2 (CUB and Sushi Multiple Domains 2) and TENM3, and one case of massive TENM2 rearrangement caused by chromothripsis, a catastrophic event leading to focal chromosome shredding. Expression of a hybrid transcript encompassing XRCC3 (X-Ray Repair Cross Complementing 3) and TENM4 sequences was detected in a further analysis of neuroblastoma (Boeva et al., 2013). Chromothripsis associated to massive rearrangements of genes between chromosomes 3 and 11, including TENM4, was also described in two small cell lung cancers (SCLCs) (George et al., 2015). Together, this evidence suggests that Teneurin genes are targets of chromosomal rearrangements in multiple solid tumors. This is consistent with the proposed fragility of large transcribed genes, and the observed tissue-specificity of Teneurin rearrangements might possibly relate to their normal, intrinsic expression patterns.

Assuming the model that predicts an overlap of common fragile sites and CNVs in large genes (Wilson et al., 2015) is pertinent, additional signs of genetic instability at Teneurin gene loci should be expected in human tumors. Among these, compelling evidence suggests that oncogenic viruses recurrently integrate at genome fragile sites throughout different cancer types (Feitelson and Lee, 2007; Dall et al., 2008). Indeed, disruption of the TENM2 gene through insertion of hepatitis $\mathrm{B}$ virus (HBV) DNA was reported in a liver sample affected by chronic hepatitis (Minami et al., 2005). As this condition can precede hepatic cancer, the presence of early genetic alterations might be considered as initiating events implicated in tumorigenesis. This notion is supported by an additional finding of HBV integration upstream of TENM2 in a hepatocellular carcinoma and its corresponding normal adjacent tissue, which might share common premalignant genetic changes (Jiang et al., 2012). HBV integration in proximity to TENM1 was detected in a fourth adjacent normal specimen, while intragenic insertion at the TENM1 locus occurred in another tumor. HBV integration in hepatocellular carcinoma was also found to target TENM4 (Zhao et al., 2016). In addition to HBV, the 4q35.1 locus encompassing part of the TENM3 gene was identified among a list of recurrent integration sites for human papilloma virus (HPV) DNA in cervix cancer cells (Jang et al., 2014). Although this study did not find fragile sites within TENM3, integration occurred in close proximity to a DNA region interacting with the chromatinbinding BRD4 (Bromodomain Containing 4) and viral E2 proteins. A genome-wide assessment of such sites revealed that they are frequently affected by deletions and that they act to nucleate viral replication foci, whereby viral integration can occur. This mechanism, involving the generation of deletions, could also overlap with a predicted presence of CNVs in the form of deletions/duplications, described as a third hallmark of large gene fragility (Wilson et al., 2015). Accordingly, TENM3 was classified as a large gene recurrently affected by deletions in low grade glioma in a study that analyzed genomic data derived from 30 tumor types (Glover et al., 2017). Nearby focal deletions at $4 \mathrm{q} 34.3$ were also recurrent in ovarian, endometrial and adrenocortical carcinoma. TENM3 instability in the form of DNA duplication has also been reported by two independent neuroblastoma studies (Molenaar et al., 2012; Pugh et al., 2013). Importantly, a statistical assessment of gene size distributions suggested that TENM3 structural alterations did not accumulate solely based on gene length, but were the result of active selection during tumorigenesis (Molenaar et al., 2012).

Considering the previous evidence, there appears to be sufficient tumor data to document Teneurin genes as recurrent sites of targeted disruption by chromosome rearrangements, through mechanisms that include translocations, CNVs, chromothripsis, and viral genome integration. Teneurins could thus fulfill criteria to be classified as large transcribed units prone to genetic instability. Additional structural determinants related to this fragility should be examined in more detail in future studies. These include sequence-based DNA motifs and epigenetic parameters such as chromosome organization (Debatisse et al., 2012; Canela et al., 2017). Further, a metaanalysis of virus integration sites confirmed the preference of HPV and HBV for transcriptionally active regions in accessible chromatin, and revealed a consistent mark of DNA methylation and specific histone modifications at these sites (Doolittle-Hall et al., 2015). We previously predicted the presence of several CpG-rich islands at the TENM2 and TENM4 gene regions (Graumann et al., 2017). Although we found no evidence of methylation-based transcriptional regulation of Teneurins in tumor cells, DNA hypomethylation might influence susceptibility to viral integration and translocation events by rendering DNA more accessible, as shown for some lymphoid malignancies (Cui et al., 2013; Lu et al., 2015). Finally, the occurrence of prevalent tandem rearrangements, defined by the involvement of genes that reside on the same strand and chromosome, has been related to an increased length of introns surrounding the fusion break points of both partner genes (Greger et al., 2014). This might explain the predominance 
of intrachromosomal rearrangements $(22 / 32,69 \%)$ observed for Teneurin genes, that harbor conserved and particularly large introns between the first predicted exon sequences (Minet and Chiquet-Ehrismann, 2000) (Figure 1A). Of 21 break points included in Table 1, 12 (57\%) occurred within intron sequences.

\section{Are Chromosomal Alterations Functionally Relevant?}

RNA-level expression data was available for most Teneurin gene rearrangements reported in tumors, but concomitant protein expression was not assessed. A potential functional contribution to tumor formation can thus only be inferred. To our knowledge, the only exception relates to $\gamma$-heregulin, a secreted TENM4/NRG1 fusion protein that displayed growthpromoting biological activity (Schaefer et al., 1997). Consistent with the finding that most Teneurin translocations were unique and involved distinct fusion partners (Table 1), $\gamma$-heregulin failed to be detected in additional breast cancer cell lines and tumor specimens (Wang et al., 1999; Sánchez-Valdivieso et al., 2002). However, the affected break region maps to a recurrent rearrangement site involving chromosomes 8 and 11 in breast and pancreatic tumors (Adélaïde et al., 2000). Further, in a subset of early-onset pancreas cancers, NRG1 rearrangement correlated with wild-type KRAS and susceptibility to pharmacologic ERBB inhibition (Heining et al., 2018). This matches the biologic behavior of MDA-MB-175 cells expressing $\gamma$-heregulin, which do not carry KRAS mutations (Hollestelle et al., 2007) and are sensitive to pertuzumab-mediated inhibition of HER3 (ERBB3) signaling in a mouse xenograft model (Lee-Hoeflich et al., 2008). Together, these data suggest that retention of TENM $4 \mathrm{~N}$-terminal sequences in $\gamma$-heregulin, which include the entire intracellular and transmembrane domains (Schaefer et al., 1997), generates a functional gene product with oncogenic activity comparable to that of other NRG1 fusion partners. Conservation of the $5^{\prime}-\mathrm{N}$ terminal TENM4 domains is recurrent to other translocations (Figure 1B).

For chromosomal alterations that lacked functional assessment, some general points should be considered. First, different outcomes would be expected for gene disrupting rearrangements, as opposed to those generating chimeric proteins through gene fusion. In the former category, gene disruption through recurrent deletion was only described for TENM3 in gliomas (Glover et al., 2017), and homozygous loss of TENM3 was also found in an embryonal rhabdomyosarcoma associated with high risk clinical parameters (Walther et al., 2016). No comparable deletion hotspots have been reported at the TENM1, TENM2, and TENM4 loci (Hazan et al., 2016). However, about one third of chromosomal translocations (Table 1) resulted in out-of-frame gene fusions. Interruption of the reading frame is typically associated with a premature translation halt leading to degradation of faulty products, through mechanisms such as nonsense-mediated mRNA decay (He and Jacobson, 2015). Rarely, translation of functional truncated proteins from such rearrangements has been documented (Mertens et al., 2015; Rodriguez-Perales et al., 2016). As Teneurin genes were in a $5^{\prime}$ position in 5/9 out-of-frame rearrangements, expression of a truncated form is unlikely, but theoretically possible. A third mechanism associated to gene disruption occurred through viral insertional mutagenesis, though the effect on Teneurin gene expression was not assessed (Minami et al., 2005; Jiang et al., 2012; Jang et al., 2014; Zhao et al., 2016). In fact, HBV appears to recurrently integrate at Teneurin gene loci. Integration of this virus was found to preferentially target cancer genes and actively transcribed genome sites, consistent with a potential gene disruptive outcome (Doolittle-Hall et al., 2015). Finally, Teneurin genes suffered massive, disruptive rearrangements through chromothripsis (Molenaar et al., 2012; George et al., 2015). When considered together, these mechanisms suggest that a subset of structural alterations might lead to inactivation of Teneurin gene expression in some tumors. The heterozygous loss of function, potentially leading to a haploinsufficient phenotype, could be consistent with a tumor suppressive role in such cases.

In contrast, a different outcome might be expected for rearrangements generating hybrid transcripts. As shown in Table 1, expression of fusion-derived RNA was asserted for 20/31 (64.5\%) translocations. Of all predicted fusion products, $13 / 32(40.6 \%)$ were in-frame and at least 2 placed novel $5^{\prime}$ UTR sequences ahead of a Teneurin gene, potentially enabling chimeric protein expression or transcriptional control through a foreign regulatory region, respectively. Interestingly, 8/9 (89\%) out-of-frame rearrangements were also detected at the RNA level, supporting their transcriptional expression. However, such forms might not be active in terms of protein production, as suggested by the low translation index of diverse out-offrame chimeras transcribed in breast cancer cells (Inaki et al., 2011), and as discussed above. With regard to translocations substituting $5^{\prime}$-UTR regulatory sequences, placement of a strong IGH promoter upstream of TENM2 was associated with at least 3-fold higher Teneurin-2 transcript levels in MALT lymphomas, as compared to tumors not bearing the translocation (Vinatzer et al., 2008). This finding is highly reminiscent of $I G H$ promoter-driven overexpression of $M Y C$, CCND1 (Cyclin D1), BCL2, and BCL6 proto-oncogenes in B-cell malignancies (Zheng, 2013). Importantly, gene translocations have been recognized as early clonal events in hematologic malignancies, and have been associated with causative roles in oncogenic transformation (Mitelman et al., 2007). Since the IGH/TENM2 rearrangement was recurrent in 3 tumors, its phenotypic impact should be investigated. The consequence of other $5^{\prime}$-UTR substitutions is less evident. Leukemias carrying the KSR1/TENM1 rearrangement showed a hybrid transcript ratio of 1.0 (Yoshihara et al., 2015), indicating lack of endogenous Teneurin-1 expression with sequencing reads solely derived from the fusion transcript. Since basal expression of KSR1 (Kinase Suppressor of Ras 1) was reported in HL60 acute promyelocytic leukemia cells (Wang et al., 2006), a transcriptionally active KSR1 promoter might be expected in leukemia and drive de novo expression of TENM1, with potential functional consequences. No equivalent expression data was specified for the KCTD21/TENM4 translocation detected in breast adenocarcinoma. In ERBB2-amplified breast cancer, expression of KCTD21 (Potassium Channel Tetramerization Domain Containing 21) was related to genomic copy number 


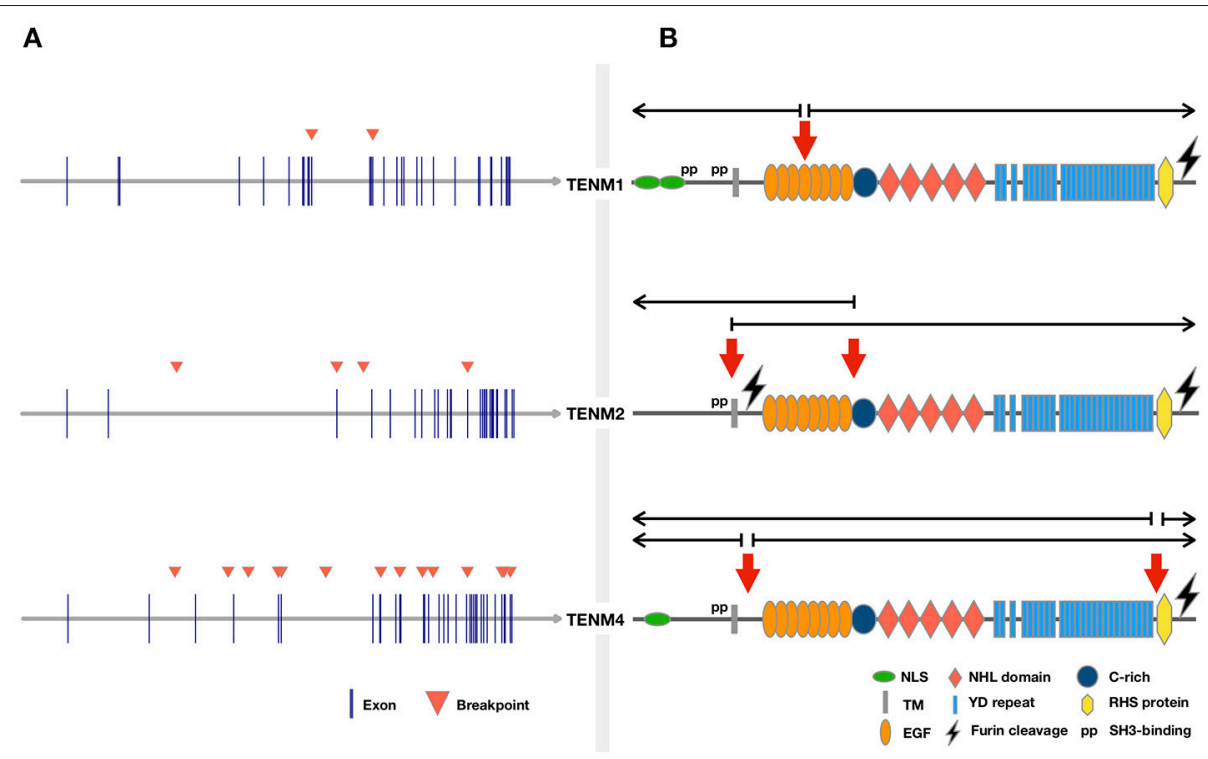

FIGURE 1 | Cancer related translocations involving Teneurin genes. Chromosomal rearrangements were retrieved from the "Atlas of Genetics and Cytogenetics in Oncology and Hematology" and ChimerDB 3.0 by gene searches for each Teneurin. Rearrangements without information on tumor origin were not included. (A) Genomic location of breakpoints from Table 1 are indicated by arrowheads. (B) Predicted location of breakpoints at protein level. Domains are based on structure proposed previously (Tucker et al., 2012). The approximate breakpoint location was estimated from the exon-to-domain correspondence shown in the ENSEMBL v.93 browser. Half open arrows over the breakpoint indicate the predicted portion of the protein retained in the resulting translocation product.

alterations (Sircoulomb et al., 2010). The corresponding 5'-UTR could thus be active in a subset of breast cancers and drive TENM4 expression in the above case. Although validation is missing, this evidence suggests that Teneurin (over)expression could be driven through foreign upstream regulatory sequences in some tumors, suggestive of an oncogenic rather than tumor suppressive role for this mechanism.

Third, almost $40 \%$ of translocations (Table 1) were predicted to generate in-frame gene fusions, which expressed a corresponding hybrid transcript in all cases where RNA was assessed. This frequency agrees with findings derived from 13 cancer types, where $36 \%$ of gene fusions were in-frame (Yoshihara et al., 2015). In the current set, 10/13 in-frame rearrangements occurred in breast tumors. The presence of chromosomal rearrangements in solid tumors has increasingly been reported in recent years and is a matter of current investigations (Mertens et al., 2015). Interestingly, mutation of relevant cancer genes was significantly reduced in breast cancers and other tumors carrying in-frame fusion transcripts, suggesting the latter could function as driver events (Yoshihara et al., 2015). In light of missing functional data to support an analogous role for Teneurin rearrangements, an indirect appraisal might be gained through the analysis of the corresponding fusion partners. Not surprisingly, most of these genes (Table 1) have been implicated in the context of malignant diseases. Among the in-frame fusion partners, EMSY (c11orf30), a BRCA2-interacting transcriptional repressor involved in DNA repair, is frequently amplified in breast, ovarian and lung cancers, where it was proposed to exert oncogenic functions (Hughes-Davies et al., 2003; Baykara et al., 2015). For the hepatitis virus A receptor gene, HVCR1, overexpression has been well-documented in clear cell renal cancer and shown to induce growth and angiogenesis-promoting factors (Cuadros et al., 2014). KIF13B, a member of the kinesin gene family, is involved in trafficking of the Vascular Endothelial Receptor 2 (VEGFR2), and disrupting this interaction has demonstrated anti-angiogenic potential in a lung tumor xenograft model (Yamada et al., 2017). Of note, a KIF13B/NRG1 fusion was identified in a liver metastasis and associated with tumor progression (Xia et al., 2017). Both KIF13B and NRG1genes can thus act as Teneurin fusion partners. For all remaining in-frame fusion partners with available cancer-related studies, equivalent results supported their oncogenic roles through over-expression or gene amplification. Only two genes showed opposite behaviors consistent with tumor suppressive functions. Hence, decreased expression of the mitochondrial transporter $\mathrm{MTCH} 2$, a pro-apoptotic gene, was associated with enhanced invasiveness and tumor progression in various tumor types (Yu et al., 2008; Arigoni et al., 2013). Similarly, RBM4 was shown to suppress tumor progression and to counter a colorectal metastatic cascade through modulation of alternative splicing (Wang et al., 2014; Lin et al., 2018), and its expression was decreased in various tumor types. For CDCD3 (Desmin), only one cancer related publication could be retrieved that reported a $M S 4 D 7 / C D C D 3$ translocation with unknown function in oropharyngeal cancer (Wang et al., 2013). For out-of-frame fusion partners, evidence for both oncogenic (ANO1, TMPRSS2) (Ko et al., 2015; Wang et al., 2017) and tumor suppressive roles (DLEC1, WWC1) (Knight et al., 2018; Li et al., 2018b) could be identified. Of note, all Teneurin fusion partner genes in the current set have been involved in additional translocations 
(documented at the "Atlas of Genetics and Cytogenetics in Oncology and Hematology," http://atlasgeneticsoncology.org/), albeit at varying frequencies. This suggests that, besides their documented roles in cancer, these genes are frequent targets of structural rearrangements in tumors with probable functional consequences. Thus, Teneurin rearrangements are not incidental and preferentially involve genes related to cancer.

Finally, additional evidence pertinent to tumor gene rearrangements should briefly be considered. Of particular relevance to Teneurins, large transcriptional units prone to breakage in cancer cells show a frequent involvement in neurological development (Smith et al., 2006). This would agree with alterations in Teneurins and other genes that regulate neuritogenesis, which were associated with an aggressive phenotype in neuroblastoma (Molenaar et al., 2012). A role in neurological development and/or disorders is also known for some Teneurin fusion partners (e.g., NRG1, NARS2, SHANK2, GRIK4, TMTC2, and KIF13B), as revealed by generelated information available at Gene Cards (https://www. genecards.org/). Further, large genes often display a high degree of evolutionary conservation, which extends to intronic sequences and fragile sites acting as preferential targets for chromosomal breakage (Greger et al., 2014; Glover et al., 2017). Not surprisingly, genome caretaker, and tumor suppressor functions have been postulated for frequently altered large genes, whose loss might provide a selective advantage to affected cells (Hazan et al., 2016; Karras et al., 2016). Gene conservation is thus considered a possible hallmark of essential cellular functions, which include the DNA damage and stress induced responses (Smith et al., 2006; Hazan et al., 2016). These features might well fit the highly conserved Teneurin genes (Tucker et al., 2012). In the particular case of Teneurin-4, gene expression further responds to conditions of endoplasmic reticulum stress, although a direct biological consequence has not been established (Wang et al., 1998). Finally, high-throughput RNA sequencing revealed that chimeric transcripts resulting from chromosomal rearrangements are expressed in a prominently tissue specific manner (Frenkel-Morgenstern et al., 2012). It was observed that chimeras often retained signal peptides and transmembrane regions, which might redirect potential hybrid proteins to unusual subcellular compartments. As shown in Figure 1B, all rearrangements retaining Teneurin intracellular domains preserved the transmembrane region, providing potential membrane anchorage to the $3^{\prime}$ fusion partner. In summary, distinct types of genomic rearrangements can lead to a range of potential outcomes for a same gene, including both oncogenic and tumor suppressive contributions to tumor development (De Braekeleer et al., 2012). Based on current evidence, a similar scenario seems highly probable for Teneurin genes.

\section{TRANSCRIPTOMIC EVIDENCE OF DYSREGULATED TENEURIN GENE EXPRESSION}

Depending on the tumor context, cancer genes can be targeted by different activating and/or inactivating mechanisms, both genetic and epigenetic. Consistent with this, altered expression of Teneurins has been reported for various tumors, in addition to structural alterations discussed above. Previously, we had reviewed transcriptomic data and reported on evidence of decreased Teneurin expression in cancers of the liver, esophagus, and kidney, while increased expression was found for brain tumors and lymphomas (Ziegler et al., 2012). With exception of increased Teneurin-2 levels related to the IGH/TENM2 translocation, accompanying data to explain the biological basis of these changes was not available. However, gene disruption through HBV insertion might be associated to reduced Teneurin2 levels in hepatocellular carcinoma and was suggested to occur early in tumor development (Minami et al., 2005). For Teneurin2, further data supported an early time point for expression changes in carcinogenesis of the breast (Lee et al., 2007), while in cervical cancer, RNA levels decreased in advanced stages with nodal compromise or the presence of metastasis (Noordhuis et al., 2011). Based on this data, a first appraisal suggested that both Teneurin up- and downregulation could occur in tumors, with a potential involvement in cancer initiating events as well as in tumor progression.

\section{Is Teneurin Gene Expression Regulated by Epigenetic Mechanisms?}

Since epigenetic modifications are a frequent cause of aberrant gene expression in tumors, we had previously analyzed the effect of a demethylating agent (5-azacytidine) on the expression of Teneurin-2 and Teneurin-4 in cancer cells (Ziegler et al., 2012; Graumann et al., 2017). Although the presence of CpGrich regions within several Teneurin genes was predicted by us and others (Beckmann et al., 2011), we found no evidence for an effect of DNA demethylation on Teneurin2 and Teneurin-4 expression in breast and ovarian cancer cell lines. However, analysis of the TENM3 promoter region revealed increased methylation in early breast lesions as compared to normal breast tissue (Tommasi et al., 2009), and in immortalized keratinocytes, Teneurin-4 gene expression could be downregulated by overexpression of DNMT3B, an enzyme involved in de novo methylation of DNA (PeraltaArrieta et al., 2017). This evidence would favor a DNA methylation-based downregulation of Teneurin expression in a manner analogous to that of other tumor suppressor genes, perhaps in a tissue-specific manner. A main drawback of these studies, however, is that concurrent analysis of DNA methylation and transcript expression were not performed, precluding conclusions on a causal relationship between both processes. To date, a single report accomplished such assessment and could demonstrate that, in a subset of glioblastoma cells, methylation of TENM1 upstream sequences was indeed inversely correlated with transcript expression (Talamillo et al., 2017). For Teneurin-1, a further role in modulating the epigenetic landscape has been proposed based on the interaction of its cleaved intracellular domain with MBD1, a nuclear CpG-binding transcriptional repressor (Nunes et al., 2005). MBD1 participates in mechanisms that regulate heterochromatin formation, and in tumors, it has been associated with silencing of tumor 
suppressor genes, promotion of oncogenic attributes, and a reduced response to cisplatin and radiation ( $\mathrm{Li}$ et al., 2015; p. 1). Interestingly, MBD1 is highly expressed in neural stem cells and its defects can impair neuron differentiation (Li et al., 2015; p. 1), underscoring its close functional link to Teneurins in non-tumor tissues. These data suggest that Teneurin-1 might be part of an epigenetic regulatory circuit, both as a modulator of gene expression and as a target of methylationbased gene silencing. However, it should be kept in mind that, owing to its cytogenetic localization, Teneurin-1 might be subjected to distinct epigenetic control mechanisms related to gender-dependent X-chromosome inactivation. Whether other Teneurin genes are regulated by equivalent methylation-based mechanisms remains to be demonstrated. As an example, differential methylation of TENM2, TENM3, and TENM4 was reported in a genome-wide analysis of neuroblastoma, but no findings for TENM1 were registered (Gómez et al., 2015). Further, methylation occurred outside of CpG islands most commonly associated with methylation-based transcriptional control, and methylation changes were not correlated with altered Teneurin gene expression. This data suggests that, although TENM1, TENM2, and TENM3 genes might show tumor-related differences in methylation patterns, per se this does not imply a concomitant change in gene expression. These aspects demand comprehensive analyses that remain to be addressed. At present, epigenetic control has been sufficiently documented only for TENM1.

\section{Uncovering Teneurin Gene Regulatory Pathways in Tumors: The NOTCH Connection}

As discussed above, DNA methylation seems not sufficient to explain tumor-related changes in Teneurin gene expression. A reasonable alternative should consider Teneurins as downstream targets of cancer-specific cellular signaling, which might impact at the level of gene expression, proteolytic protein processing, or the regulation of specific domain activity by posttranslational modifications, among others. This would be consistent with the fact that Teneurin translocation partners were enriched in cancer-related genes, which delineates a well-described oncogenic mechanism. With regard to signaling pathways, vast structural and functional parallels between Teneurins and Notch proteins have recurrently been noted, which include their analogous transmembrane localization, their capability to dimerize upon ligand interaction, the presence of multiple epidermal growth factor-like (EGF) repeats in their extracellular domains, and their processing into multiple domains through proteolytic cleavage (Tucker and Chiquet-Ehrismann, 2006; Schöler et al., 2015; Vysokov et al., 2016). These associations were recently shown to reach deeper, as overexpression of the NOTCH1 intracellular domain, which functions in a nuclear transcription activator complex, revealed that TENM4 is a NOTCH-responsive gene (George et al., 2015). The authors proposed that $\mathrm{NOTCH}$ signaling acts as a key regulator of neuroendocrine differentiation in small cell lung cancer. This seems consistent with a potential effector role of Teneurins, considering their essential participation in neural development (Tucker et al., 2007). TENM4 responsiveness to NOTCH signaling was also noted in muscle satellite cells, where both were required for maintenance of cell quiescence and inhibition of myogenic differentiation (Bröhl et al., 2012; Ishii et al., 2015). In small cell lung cancer, NOTCH signaling was ascribed a tumor suppressive role, and as a NOTCHregulated gene, an equivalent function might be expected for TENM4. Notably, the similarities between both gene families go well-beyond the observations outlined above, and could define a highly probable setting governing Teneurins' involvement in cancer. As recently reviewed in great detail (Nowell and Radtke, 2017), the contribution of NOTCH-mediated signaling is particularly dependent on the cellular and tumor context, with both oncogenic and tumor suppressive outcomes. Oncogenic activation can occur through chromosome translocations or activating $\mathrm{NOTCH}$ mutations in leukemia, while inactivating mutations occur in tumors where it exerts a tumor suppressive role, such as in small cell lung cancer (George et al., 2015). Further, NOTCH4 is a target for mouse mammary tumor virus (MMTV) integration in mice, and $\mathrm{NOTCH}$ gene expression can be altered by some HPV viral proteins, unveiling a role for viral-dependent mechanisms that shows remarkable similarities with Teneurins. The phenotypic contribution of NOTCH dysregulation could relate to its ability to negatively and positively regulate differentiation and stem cell fate, in analogy to the role of Teneurins in modulating cellular differentiation in different cell types (Suzuki et al., 2012, 2014a; Ishii et al., 2015; Tews et al., 2017). Not surprisingly, expression of NOTCH family genes has been associated with clinical parameters and patient outcome in cancer. Based on the vast implications of NOTCH signaling in malignant diseases, this pathway is a current target for development of directed therapeutic interventions.

\section{Teneurin Expression Is Associated With Biological and Clinical Parameters}

Assuming that Teneurins are active players in tumorigenesis through mechanisms analogous to NOTCH, similar biological and clinical findings would be expected for this gene family. Not surprisingly, Teneurin expression has been related to tumor behavior and patient survival in several cancer types. In invasive and aggressive-invasive prolactin pituitary tumors, upregulation of Teneurin-1 mRNA was associated with tumor progression (Zhang et al., 2014), and a similar observation was made for papillary thyroid cancer (Cheng et al., 2016). In the latter case, Teneurin-1 expression was further associated with extra-thyroidal invasion, an advanced disease stage, the risk of recurrence, and the presence of $B R A F \mathrm{~V} 600 \mathrm{E}$, an actionable mutation with a known prognostic significance in this cancer. For Teneurin-3, decreased levels predicted a worse survival in neuroblastoma patients (Molenaar et al., 2012), while expression was upregulated in breast tissue of nulliparous women, known to be at higher risk of developing breast cancer (Balogh et al., 2006). Interestingly, differentiation of breast tissue is not fully accomplished in these women and maintains a high proportion of stem cells, suggesting that upregulation of Teneurin-3 
might relate to an altered differentiation process, as discussed above. In the same line, we found a decrease in Teneurin-4 expression in high grade serous ovarian tumors that undergo dedifferentiation, and reduced Teneurin-2 levels predicted a poor survival in these patients (Graumann et al., 2017). To retrieve additional prognostic associations, we performed a gene-based query at the Human Protein Atlas (https://www.proteinatlas. org/pathology), which provided statistical correlations of patient survival based on quantitative analysis of transcriptomic data. Table 2 summarizes Log-rank $p$-values based on either optimal or median separation of low and high-expressing tumor groups, providing evidence for significant prognostic implications of Teneurin expression in a range of different cancers. Interestingly, all four Teneurins were associated with patient survival in cancers of the endometrium, kidney and stomach, and with the exception of Teneurin-3 in renal cancer, survival was improved for patients with low Teneurin levels, possibly hinting to a common underlying mechanism. These findings raise the question whether all Teneurins were concomitantly expressed in these tumors. At least in some cell lines, we could demonstrate a simultaneous expression of Teneurin-2 and Teneurin-4 (Graumann et al., 2017), and coexpression of different Teneurins was also noted in one neuroblastoma cell line (Suzuki et al., 2014b), although the functional implications remain unknown. In contrast, other tumors showed an apparent gene-specific association, such as melanoma and colorectal cancer (Teneurin2 only) and cervical cancer (Teneurin-3 only) (Table 2). About one third of cancers showed a better survival upon increased Teneurin expression, suggesting a distinct biological behavior for this group. Hence, results based on transcriptomic analysis of large TCGA patient cohorts strongly support an involvement of Teneurins in tumor biology, evidenced through their prognostic association with patient survival and tumor differentiation. It is highly probable that, as additional cancer types will be analyzed in sufficiently large numbers, new findings will emerge in a near future. Based on current data, it is conceivable that Teneurins' role in tumorigenesis could relate to their ability to modulate cell differentiation, in addition to other processes discussed below.

\section{Cancer Pathways: Interaction Points of Teneurins and WNT Signaling}

Considering the above associations with clinicopathological parameters, it seems reasonable that cancer-related biological mechanisms might regulate-or be regulated by-Teneurins. Besides the dazing relation between Teneurins and NOTCH, several studies are consistent with this prediction. For instance, in node-positive, poor prognosis cervical cancers, Teneurin-2 levels were increased together with CTNND1 (Noordhuis et al., 2011), a member of the catenin gene family that stabilizes ECadherin at epithelial adherens junctions and mediates noncanonical WNT signaling (Schackmann et al., 2013). Upon ECadherin loss, CTNND1 mislocalizes to the cytoplasm and aberrantly regulates Rho-mediated signals, leading to the induction of a migratory and invasive phenotype through epithelial-mesenchymal transition (EMT). Interactions between
TABLE 2 | Significant associations between Teneurin transcript levels and patient survival.

\begin{tabular}{|c|c|c|c|c|}
\hline Gene & $\begin{array}{l}\text { Cancer } \\
\text { type }\end{array}$ & $\begin{array}{c}\text { Optimal } \\
\text { separation } \\
p \text {-value }\end{array}$ & $\begin{array}{c}\text { Median } \\
\text { separation } \\
p \text {-value }\end{array}$ & $\begin{array}{c}\text { Better } \\
\text { survival } \\
\text { outcome* }^{*}\end{array}$ \\
\hline \multirow[t]{10}{*}{ TENM1 } & Breast & $1.71 \mathrm{E}-03$ & 7.89E-03 & High \\
\hline & Endometrial & 8.68E-04 & 6.37E-03 & Low \\
\hline & Glioma & 7.73E-03 & 1.86E-01 & Low \\
\hline & $\begin{array}{l}\text { Head } \\
\text { and neck }\end{array}$ & 3.51E-02 & 4.89E-02 & High \\
\hline & Lung & 2.68E-04 & 6.36E-03 & High \\
\hline & Pancreatic & 4.49E-03 & 5.91E-02 & High \\
\hline & Renal & 2.71E-02 & 8.98E-01 & Low \\
\hline & Stomach & 4.41E-02 & 7.08E-01 & Low \\
\hline & Thyroid & 3.25E-03 & 4.46E-01 & High \\
\hline & Urothelial & 4.44E-02 & 1.92E-01 & Low \\
\hline \multirow[t]{12}{*}{ TENM2 } & Colorectal & 2.94E-02 & 2.85E-01 & High \\
\hline & Endometrial & 9.16E-03 & 4.32E-02 & Low \\
\hline & Glioma & $6.28 \mathrm{E}-03$ & 5.19E-02 & Low \\
\hline & $\begin{array}{l}\text { Head } \\
\text { and neck }\end{array}$ & 3.81E-03 & 6.85E-02 & Low \\
\hline & Melanoma & 4.62E-02 & 4.62E-02 & Low \\
\hline & Ovarian & 2.10E-02 & 2.40E-01 & High \\
\hline & Pancreatic & $3.68 \mathrm{E}-03$ & 2.37E-01 & High \\
\hline & Prostate & 4.34E-02 & 2.83E-01 & High \\
\hline & Renal & 4.69E-05 & 1.04E-02 & Low \\
\hline & Stomach & 3.47E-02 & 5.78E-01 & Low \\
\hline & Thyroid & 5.16E-04 & $1.72 \mathrm{E}-01$ & Low \\
\hline & Urothelial & 7.52E-04 & 2.57E-03 & Low \\
\hline \multirow[t]{10}{*}{ TENM3 } & Cervical & 3.01E-02 & 5.25E-01 & High \\
\hline & Endometrial & 4.43E-02 & 4.99E-01 & Low \\
\hline & Glioma & 1.26E-02 & 3.91E-02 & Low \\
\hline & Lung & 8.68E-03 & 7.39E-02 & Low \\
\hline & Ovarian & 2.31E-02 & 6.79E-02 & Low \\
\hline & Pancreatic & 4.85E-02 & 3.81E-01 & High \\
\hline & Renal & 4.10E-02 & 3.54E-01 & High \\
\hline & Stomach & $1.47 \mathrm{E}-03$ & 5.67E-02 & Low \\
\hline & Thyroid & 1.07E-02 & 7.42E-02 & Low \\
\hline & Urothelial & 5.25E-04 & 6.37E-02 & Low \\
\hline \multirow[t]{4}{*}{ TENM4 } & Endometrial & 2.96E-03 & 7.21E-01 & Low \\
\hline & Liver & 1.18E-02 & 4.87E-02 & Low \\
\hline & Renal & 6.51E-03 & 7.17E-02 & Low \\
\hline & Stomach & 5.40E-03 & 4.71E-02 & Low \\
\hline
\end{tabular}

* "High" and "Low" refer to Teneurin transcript expression level groups according to applied threshold, defined by either Optimal separation or Median expression levels.

Teneurins and WNT signaling are also relevant to normal embryonal development. Hence, Teneurin-4 was a main binding partner of Olfactomedin-1 (OLFM1), a secreted glycoprotein involved in regulation of proliferation and differentiation of neural progenitor cells in the brain, and proposed to regulate small GTPase RhoA activity and WNT signaling (Nakaya et al., 2013). In avian limb development, a potential interaction between the WNT7A ligand and Teneurin-1 or Teneurin-3 
was suggested based on their expression in common cellular compartments (Bagutti et al., 2003). A similar association might be deduced from the concomitant decrease in WNT7A and Teneurin-4 expression observed in neurons of schizophrenia patients obtained by in vitro differentiation (Brennand et al., 2011). Further, defects in WNT7A impair female genital tract development and have been associated with Müllerian duct anomalies in mice (Choussein et al., 2017), while in C. elegans, disruption of Ten-1 impairs development of somatic and germline gonadal cells (Drabikowski et al., 2005). These data suggest that during development, Teneurin expression might respond to WNT7A-mediated signals in some common compartments, thereby altering biological processes such as cell adhesion and migration. However, these associations do not always hold and especially in tumors, the role of WNT7A is more complex as it can exert opposite oncogenic as well as tumor suppressive functions (Stewart, 2014; Huang et al., 2018). In fact, Teneurin-1 and EMX2 levels were highly increased and HOXA10 levels were reduced in women with Müllerian defects leading to a partially separate uterus (Zhu et al., 2016). Activity of the homeobox transcription factor HOXA10, a direct negative regulator of EMX2 gene expression, is dependent on an intact WNT7A function (Miller and Sassoon, 1998). In turn, EMX2 is a direct activator of TENM1 transcription (Beckmann et al., 2011). This would define an opposite signaling cascade where WNT7A positively regulates HOXA10 function, leading to repression of EMX2 and its downstream targets, including Teneurin-1. Since EMX2 has an antiproliferative function in endometrial cells (Taylor and Fei, 2005), its elevated expression seems consistent with the impaired cell growth associated with Müllerian duct anomalies, where Teneurin-1 could act as growth restricting downstream effector. Equally, Kaplan-Meier estimates available at The Human Protein Atlas (https://www.proteinatlas. org/pathology), register improved survivals for patients with endometrial cancer expressing high EMX2 (log-rank test $P=$ $0.0054)$ and low WNT7A $(P=0.00003)$ levels, indicating an advantage of persistent antiproliferative signals. However, the same does not hold for Teneurin-1, whose low expression was associated with improved survival in these patients (Table 2). This result further contrasts findings in C. elegans, where germline tumors resulted upon deletion-mediated loss of expression of the Ten-1 ortholog (Drabikowski et al., 2005). Thus, prognostic conclusions can not necessarily be extrapolated from predicted pathway interactions and must consider additional factors, as exemplified by the finding of both positive and inverse associations between Teneurins and WNT7A in different cellular contexts.

Recently, a deeper insight has been provided into molecular mechanisms underlying the role of Teneurin-1 in cancer. The authors showed that in glioblastoma cells, loss of Teneurin1 expression through chromosomal deletion or epigenetic silencing was associated with resistance to serum-induced differentiation (Talamillo et al., 2017). Although exogenous Teneurin-1 expression restored a differentiated phenotype, it provided cells with an enhanced migratory and invasive potential, suggesting a fine equilibrium between Teneurin1 -mediated regulation of differentiation fate and migratory capacity. Further, increased Teneurin-1 levels were predictive of a poor outcome in glioblastoma patients and xenograft models, consistent with transcript-based survival estimates for glioma patients (Table 2). Strikingly, the cleaved intracellular (ICD) but not the extracellular Teneurin-1 domain was capable of eliciting the migratory and invasive properties, as well as a rearrangement of the actin cytoskeleton, the expression of mesenchymal markers, and an increased resistance to toxicity mediated by the alkylating agent temozolomide. In functional terms, the Teneurin-1 ICD acted in the nucleus through direct interaction with the MYC oncoprotein, inducing transcriptional activation of the small GTPase RHOA gene. These findings place Teneurin1 as an executor of MYC-RHOA-induced responses, which are associated with oncogenic signaling through WNT pathways in glioblastoma, although additional components of this pathway were not analyzed (Lee et al., 2016). This study strengthens the above evidence of a functional link between Teneurins and WNT signaling, and points to the relevance of proteolytic processing in the generation of Teneurin domains with distinct functional attributes. Similar findings had been described earlier for the Teneurin-2 and Teneurin-3 ICDs, which were implicated as negative regulators of ZIC1 function and ZIC2 expression, respectively (Bagutti et al., 2003; Glendining et al., 2017). The ZIC transcription factors appear to accomplish mainly tumor suppressive roles, but overexpression occurs in some cancers, suggesting an alternative oncogenic function (Houtmeyers et al., 2018). At least for the Teneurin-3 ICD, a direct interaction with ZIC2 could be demonstrated in vitro (Glendining et al., 2017). Interestingly, the activity of ZIC transcription factors can be inhibited in C. elegans neural progenitors by WNT downstream effectors B-catenin and TCF (Murgan et al., 2015), raising the possibility that Teneurin ICDs might act as part of this protein complex to modulate transcription factor activity. In addition, Teneurin-3 knock-out experiments showed that its ICD can act as a positive and negative regulator of Ephrin receptors EPHA7 and EPHB1 expression, respectively (Glendining et al., 2017). The concomitant decrease in ZIC2 and EPHB1 is consistent with the positive regulatory role that ZIC2 exerts on EPHB1 transcription (García-Frigola et al., 2008). Ephrin receptors activate signaling cascades through RHOA, AKT and ERK, to regulate cell growth, migration, and EMT, and their expression is altered in numerous tumor types (Kou and Kandpal, 2018). Hence, modulation of Ephrin-mediated processes provides an additional explanation of Teneurins contribution to tumor development. Further, the distinct activities of cleaved Teneurin ICDs imply that their preservation in chromosomal translocation products (Figure 1B) might actively contribute to oncogenic functions, through ICD-mediated transcriptional modulation of relevant target genes (Bagutti et al., 2003). Since proteolytic release of the Teneurin-2 ICD can be promoted by homophilic interactions (Bagutti et al., 2003), it should be examined if alternative ligand-dependent mechanisms operate in tumor cells, perhaps as the result of Teneurin interactions with components of the extracellular matrix (ECM). Thus, current evidence supports a role of Teneurins as mediators or effectors of WNT signaling, which might be associated with tumor suppressive as well as oncogenic outcomes. We had previously proposed 
a model to describe such potential interactions (Ziegler et al., 2012).

\section{Teneurins and Modulation of Neuregulin-ErbB-Mediated Signaling}

In cancer cells, different signaling pathways often converge at common cross-points to establish complex regulatory networks. It is thus not surprising that Teneurins might appear in different molecular contexts directed at a common functional endpoint. As noted above, a hybrid NRG1/TENM4 fusion product $(\gamma$-heregulin) displayed growth promoting activity on different tumor cell lines (Schaefer et al., 1997). Although these experiments focused on growth stimulation associated with the secreted Neuregulin-1 ligand, it should be recalled that proteolytic cleavage of $\gamma$-heregulin would simultaneously generate a membrane anchored Teneurin-4 ICD, which might exert additional roles to support oncogenic transformation. Interestingly, NRG signaling through ERBB receptors accomplishes crucial functions in nervous system development that are highly reminiscent of Teneurins (Mei and Nave, 2014). Moreover, single nucleotide variants (SNVs) in NRG and ERBB genes have been associated with an increased risk of psychiatric conditions such as schizophrenia and bipolar disorder (Mei and Nave, 2014), analogous to findings reported for Teneurin-4 (Psychiatric GWAS Consortium Bipolar Disorder Working Group, 2011; Ivorra et al., 2014). Similarly, neurons from schizophrenia patients differentiated in vitro showed misexpression of various genes including TENM4, NRG1 and ERBB4, suggestive of a functional connection between these proteins. A similar association might be inferred from experiments with overexpression of the Teneurin-1 ICD in glioblastoma cells, which lead to an increased transcriptional activation of melanogenesis-associated transcription factor (MITF) target genes, including ERBB3 (Schöler et al., 2015). Teneurins might thus support this oncogenic pathway by promoting the expression of ERBB receptors to provide sufficient binding sites for NRG ligands. In line with this notion, a recent study using CRISPR-CAS9 to knock-out ZEB1, a homeobox transcription factor that mediates epithelial to mesenchymal transition (EMT) in response to TGF- $\beta$, found that Teneurin-2 transcription is directly repressed by ZEB1 in triple-negative breast cancer cells (Maturi et al., 2018). Interestingly, ERBB4 expression increased over 5-fold upon ZEB1 knockout, with a concomitant 16-fold increase in Tenerin-2, which agrees with the association proposed for these gene families. In the case of breast cancer, it is interesting to speculate that the positive prognostic impact of Teneurin-1 overexpression (Table 2) might be associated with a simultaneous expression of ERBB receptors, which provide an actionable target for directed therapies able to positively impact on patient survival (Hynes, 2016). This interaction illustrates how additional factors can modify an expected prognostic impact predicted by molecular parameters. As a further example, ZEB1 knock-out cells showed diminished invasiveness and a delayed migratory behavior, which might predict a positive prognostic impact of Teneurin-2 reexpression. However, the opposite was true in a small group of patients with triple-negative breast cancer, where increased Teneurin- 2 was associated with shorter metastasis-free survival (Maturi et al., 2018). A possible explanation might relate to the poor prognostic impact of ERBB4 expression in triple negative breast cancer patients receiving standard, non-targeted treatment regimens (Kim et al., 2016). In the former study, the therapeutic modalities were not specified and preclude assessment of this variable, which might modify the prognostic impact of Teneurins in a treatment-dependent manner (Maturi et al., 2018).

If the proposed association holds, Teneurins would be linked to additional cancer signaling pathways, as NRG1/ERBBdependent phosphorylation triggers PI3K/AKT and MEK/ERKmediated responses (Roskoski, 2014). This interaction should be analyzed in depth in normal and tumor cells, as it involves essential mechanisms in both contexts. To analyze if coexpression of Teneurin and ERBB genes occurs frequently in tumors, transcriptomic analyses of larger sample groups are required and should consider the therapeutic modalities received by patients as key determinants of patient outcome. The molecular role of Teneurin ICDs in mediating transcriptional activation of ERBB genes should also be assessed.

\section{Additional Functional Considerations}

Another aspect to be considered is the well-documented interaction of Teneurins with cytoskeletal and extracellular matrix (ECM) components, which could bear potential relevance to cancer. Hence, a role for Teneurins in cell migration was recognized early in Drosophila, as heterophilic interaction of Ten-m with PS2 integrins was shown to promote cell spreading (Graner et al., 1998). Further, disruption of Ten-m or the actincrosslinking protein Filamin resulted in a comparable phenotype characterized by altered cell migration and routing of motor neurons (Zheng et al., 2011), suggesting a connection between Teneurins and the actin-based cytoskeleton in cell motility. The authors could also demonstrate that Filamin and Ten$\mathrm{m}$ physically interact in epidermal cells. Interestingly, actin cytoskeleton dynamics appears to be regulated by both the Teneurin-1 ICD (Talamillo et al., 2017) and the Teneurin Cterminal associated peptide (TCAP-1) (Chand et al., 2012). These constitute two structurally unrelated domains located on opposed Teneurin protein termini, derived either through proteolytic cleavage or by transcription from alternative intronic promoters. In mouse hypocampal cells, cellular effects of the secreted TCAP1 domain were mediated by interaction with a dystroglycan receptor complex. This elicited the activation of MEK and ERK-dependent signaling, leading to filamin phosphorylation and actin polymerization required for outgrowth of cellular protrusions. In contrast, the Teneurin-1 ICD acted through its proposed nuclear role in transcriptional regulation by inducing $R H O A$ gene expression, with resulting activation of Rho-dependent kinase (ROCK) signaling and remodeling of the actin cytoskeleton. In this case, glioblastoma cells acquired features of increased tumor cell aggressiveness, as discussed above. No evidence is currently available to support the concomitant activity of TCAPs and Teneurin ICDs in tumors or normal tissues. TCAPs are bioactive peptides capable of eliciting intracellular signals that could be relevant to tumorigenesis (Wang et al., 2005). These issues deserve further clarification and 
illustrate the complex mechanisms that underlie the activity of Teneurins.

With regard to interaction of Teneurins with components of the extracellular matrix (ECM), the integrity of basal membrane structures in C. elegans was dependent on the interaction of Ten-1 at the surface of epidermal cells with collagen IV in the extracellular space (Topf and ChiquetEhrismann, 2011). Conversely, Teneurin-4 was shown to negatively regulate expression of collagens type II and X through mechanisms involving ERK-dependent signaling, which was associated with suppression of chondrogenic differentiation and preservation of a mesenchymal phenotype (Suzuki et al., 2014a). Thus, Teneurins can alter determinants of cell adhesion and migration, which are essential targets in tumor cells, by direct interaction and modulation of components of the ECM. Interestingly, a proteomic study revealed a prominent increase of membrane-associated Teneurin-1 upon activation of platelets with a collagen-related peptide (Wright et al., 2011). Platelets are important promoters of tumor development through mechanisms that include the release of proangiogenic and growth promoting factors (Plantureux et al., 2018). Further, platelets adhere to tumor cells and protect them against mechanical forces and immune surveillance in the bloodstream, providing an essential contribution to metastatic spreading. The adhesion of tumor cells to platelets is mediated by various cell surface molecules such as integrins, P-selectin, and podoplanin. Since Teneurins engage in homophilic and heterophilic interactions that can mediate intercellular adhesion (Rubin et al., 2002; Boucard et al., 2014), they might facilitate the contact of platelets with tumor cells and promote tumor metastasis. The reported interaction of Teneurins with integrins seems consistent with such mechanism (Graner et al., 1998; Trzebiatowska et al., 2008), as specific integrin subtypes are expressed in tumor cells and on the platelet surface (Wright et al., 2011). A crossing point of Teneurins and integrins is supported by additional data. Hence, focal adhesion kinase (FAK)-dependent signaling was induced by Teneurin- 4 in neuroblastoma cells, and phosphorylated FAK colocalized with Teneurin-4 at sites of neurite protrusion formation, together with the Rho GTPases cdc2 and Rac1 (Suzuki et al., 2014b). Integrin-mediated signaling commonly activates the FAK pathway, and inhibition of oncogenic FAK activity bears therapeutic importance (Kolev et al., 2017). Further, Rho GTPases are key regulators of cell migration (Sadok and Marshall, 2014) and have been implicated in several contexts as mediators of Teneurin functions (Nakaya et al., 2013; Glendining et al., 2017; Talamillo et al., 2017), as discussed above. In addition, the Teneurin-1 ICD was shown to bind to CAP/Ponsin (Nunes et al., 2005), a cytoskeleton adaptor molecule that interacts with FAK to regulate focal adhesion and cytoskeleton dynamics, thus impacting on cell adhesion and migration (Tomasovic et al., 2012). Finally, Teneurin- 4 and Laminin, the common ligand for integrins, showed partly overlapping localization patterns in the developing avian gut (Kenzelmann-Broz et al., 2010), and in C. elegans, evidence suggested that laminin Epi1 might act as a Ten-1 ligand (Trzebiatowska et al., 2008). Together, these findings suggest that Teneurins modulate and interact with components of integrin mediated signaling to modify crucial components required for cell migration and invasion. The localization of Teneurins at essential sites of cytoskeletal anchorage, focal adhesion, and attachment to the extracellular matrix, is consistent with this role. Teneurinmediated adhesion is actively involved in cell signaling through well-characterized cancer-related pathways. Such signals might be initiated by context-dependent, hemophilic, or heterophilic intercellular contacts between Tenerins and/or integrins, or by Teneurin-mediated signaling derived from interaction with ECM components such as collagens.

The role of Teneurins as modulators of cytoskeleton dynamics might also be relevant to drug-resistance, where microtubules play an important part. As showed in Drospohila, Teneurin disruption lead to disorganized microtubule and $\alpha$-spectrindependent cytoskeletal structures that impaired transsynaptic organization (Mosca et al., 2012), and in mouse hippocampal cells, TCAP-1 increased levels of tubulins alfa and beta at cellular protrusion sites (Chand et al., 2012). Further, the microtubuleactin cross-linking factor 1 (MACF1) protein was identified as a Teneurin-1-ICD binding protein (Schöler et al., 2015). Interestingly, interaction with MACF1 would strengthen the link of Teneurins with ERBB-mediated signaling, as in breast cancer cells, $B$-heregulin could induce ERBB2-dependent protrusions that were enriched in microtubules (Zaoui et al., 2010). It could be shown that MACF1 acted as a downstream effector of ERBB2 signaling that mediated microtubule capture at the cell membrane. MACF1, which is highly expressed in the developing nervous system, is further required for WNT-signaling (Chen et al., 2006), whose involvement with Teneurins was discussed above. MACF1 expression was also prominent at advanced stages in brain tumors, including glioblastoma (Afghani et al., 2017). The authors showed that MACF1 knock-out could reduce proliferation and migration of glioblastoma cells, which was accompanied by a reduction in WNT signaling effectors. Further, downregulation of MACF1 increased sensitivity of glioblastoma cells to the DNA alkylating agent temozolomide. Since overexpression of the Teneurin-1-ICD increased resistance to this drug in glioblastoma (Talamillo et al., 2017), interaction of Teneurin-1 and MACF1 might contribute to this phenotype, possibly involving the stabilization of actin and microtubule cytoskeletal structures and WNT signaling activity. A role for Teneurins in drug resistance is also supported by the massive overexpression (> 200-fold) of Teneurin-2 in an ovarian cancer cell line resistant to vincristine, a microtubule-targeting vinca alkaloid (Buys et al., 2007). In addition to increases in transporter genes, Fibronectin-1 was also massively augmented, which lead the authors to propose a cell adhesion mediated drug resistant (CAM-DR) phenotype, in which anchorage to the ECM appears essential for cell survival in the presence of antineoplasic drugs. Interestingly, Lathrophilin-3 and several collagens were also upregulated, suggesting that Teneurins could interact in a common pathway with these adhesion molecules to mediate drug resistance related to adhesion. Consistent with this prediction, CAM-DR involves signaling through MEK/ERK and FAK pathways (Dickreuter and Cordes, 2017) and in breast cancer, upregulation of Teneurin-related Tenascin-C was implicated (Jansen et al., 2005). Also, the Ephrin receptor-A4 
(EPHA4) was required for CAM-DR in multiple myeloma (Ding et al., 2017), and Teneurins are known regulators of Ephrin receptor expression in structures of the visual system (Young et al., 2013; Glendining et al., 2017). In this context, Teneurin-2 knock-out caused concomitant reductions in EPHB1 and CFOS, and the latter was also reduced upon Teneurin-3 knock-out (Merlin et al., 2013; Young et al., 2013). This suggests that expression of the oncogenic transcription factor c-Fos, which is a target of ERK-mediated phosphorylation, might be under transcriptional regulation of Teneurins. These findings again highlight the role of MEK-ERK signaling as a central component of Teneurin-mediated functions in tumors. The transcriptional regulation of Ephrin receptors, whose expression is frequently augmented in tumors, might provide a further mechanism of CAM-DR promotion through Teneurins.

In summary, altered expression of Teneurins has been demonstrated in numerous tumors and can be an early event in cell transformation. Recent data have provided new functional insights demonstrating that Teneurins respond-to and can orchestrate signaling pathways with known roles in carcinogenesis, invasion and drug resistance. Not surprisingly, Teneurin expression is associated to patient outcome and could bear prognostic implications. In future studies, distinct and domain-specific functions must be considered that involve Teneurin-mediated transcriptional regulation, extracellular signaling, and adhesion between cells and with components of the extracellular matrix. Consistent with this complex scenario, both up- and downregulation of Teneurins can be expected in tumors, and their dual tumor suppressive or oncogenic function might parallel that of other proteins implicated in cancer.

\section{TENEURINS AS TARGETS OF SOMATIC MUTATION}

As evidenced in the above sections, tumor-related Teneurin alterations conform to mechanisms expected for typical cancer genes, which include changes in gene structure and expression levels suggestive of both oncogenic and tumor suppressive functions. If these predictions hold, it should be possible to identify additional mechanisms common to cancer genes, such as sequence changes through somatic mutation. The analysis of such findings presents some difficulties. First, Teneurins are encoded by very large genes. In probabilistic terms, this means that large DNA sequence stretches might be expected to show a proportionally high number of variants throughout the entire gene length, affecting different domains of the encoded protein. Second, functional studies to address the impact of every such change do not exist or are limited to different contexts, as will be discussed. Similarly, there is insufficient evidence to catalog single nucleotide variants as benign causes of genetic variation, or instead, as pathogenic somatic changes. In spite of these limitations, records of somatic alterations can be retrieved from large databases and subjected to a comparative analysis, as we expose below.

\section{The Impact of Single Nucleotide Variants}

Considering the unknown functional impact of Teneurin SNVs in tumors, supportive evidence can be inferred from the analysis of variants in other pathogenic conditions. As mentioned, Teneurin genes are strongly conserved throughout species (Minet and Chiquet-Ehrismann, 2000; Tucker et al., 2012) and sequence variation might thus impact on protein function. Accordingly, a novel variant in TENM3 was associated with developmental defects of the visual system leading to small eyes (microphtalmia) and impaired vision (Aldahmesh et al., 2012). The variant (p.T695Nfs*5) introduced a frameshift mutation resulting in a premature stop codon at the extracellular side of the Teneurin-3 transmembrane domain. It was shown to completely abolish TENM3 gene expression, although the intracellular and transmembrane domains were correctly encoded. Since the variant was homozygously inherited in two affected siblings, it resulted in a null phenotype with complete absence of Teneurin3. This phenotype is consistent with impairments in the visual system observed in Teneurin-3 knock-out mice (Leamey et al., 2007; Glendining et al., 2017). In terms of frequency, the mutation could not be found in healthy controls or in a database with variant coverage derived from $>10.000$ chromosomes, which supported it was an uncommon, pathogenic change. Some years later, 12 novel missense variants in TENM4 were discovered in Spanish patients affected with essential tremor (Hor et al., 2015), a phenotype also observed in mice upon Teneurin4 knock-out (Suzuki et al., 2012). Unlike microphtalmia, this condition was inherited in an autosomal dominant fashion, and eleven variants were predicted to be damaging by various in silico algorithms. Three variants were characterized further and showed a trend to altered Teneurin- 4 protein clustering at cell membranes. Further, they increased the number of smalldiameter neuronal axons and induced errors in branching and pathfinding in zebrafish, consistent with previous findings in Teneurin-4 knock-outs. The authors suggested a dominantnegative effect possibly related to an impaired ability of Teneurin4 to engage in homophilic interactions, as two of the variants (p.T1367N, p.A1442T) altered essential NHL-repeat/ $\beta$ propeller motifs in the extracellular domain. In contrast, TENM4 variants could not be associated with essential tremor in Canadian patients (Houle et al., 2017). In this cohort, missense variants were more frequent in cases (25\%) than controls (14\%), but could not be statistically associated with disease. One shortcoming was that variant segregation in cases and their relatives was not assessed. With few exceptions, missense changes were present in 1 or 2 individuals only, and nonsense variants were extremely rare with only one identified case. This suggests that deleterious loss of function changes are not well-tolerated in the germline and might be subjected to negative selection (Martincorena et al., 2017), while missense variants were more frequent but occurred at low allelic frequencies. The nonsense mutation generated a premature stop codon close to the Teneurin-4 Cterminus, which should preserve the largest portion of the protein intact. This bears similarity to a missense variant affecting a conserved residue within the globular C-terminal domain of murine Teneurin-4, which lead to embryonic failure due to severe 
gastrulation defects (Lossie et al., 2005). An additional missense variant within the Teneurin-3 C-terminal TCAP-domain was recently found to segregate with developmental dysplasia of the hip in a large pedigree with severe manifestations (Feldman et al., 2017). Interestingly, the cytogenetic localization of TENM3 maps to a locus previously associated with this dysplastic condition, where at least one additional gene has been implicated (Zhao et al., 2017). These data suggest that, although a major part of the protein might not be affected, alterations at Teneurin C-terminal domains should not be dismissed in terms of potential phenotypic impact. Besides TCAPs, an apoptogenic C-terminal domain was recently described for Teneurin-2 (Ferralli et al., 2018). The physiologic stimuli triggering its release remain unknown, but the domain was proposed to model neural networks through selective induction of apoptosis at intersynaptic spaces. Finally, a rare missense variant in TENM1 was associated with a familial case of congenital general anosmia (Alkelai et al., 2016). This variant (p.P1610L) had not been reported in the population and was categorized as damaging by eight predictive algorithms. According to current gene annotations, this change would localize amidst conserved tyrosine-aspartic acid (YD) repeat motifs. These repeats, best known from bacterial proteins, appear to be glycosylated and to mediate cellular aggregation (Feng et al., 2002; Rubin et al., 2002). Taken together, these reports demonstrate that SNVs in Teneurin genes can result in pathogenic outcomes, although the mechanisms involved have not been studied in depth. A potential functional redundancy between different Teneurins should also be considered, which might constrain the phenotypic severity derived from single pathogenic variants (Leamey et al., 2007; Trzebiatowska et al., 2008).

\section{Recurrent Somatic Changes in Lymphoma}

The above examples of microphtalmia and essential tremor represent homozygous loss of function as opposed to heterozygous, dominant function gain, respectively. In cancer, such changes would match mechanisms of tumor suppressor loss and oncogene activation, triggered through acquisition of somatic mutations. Two studies addressing the mutational landscape in lymphomas have listed somatic variants in Teneurins. The first performed whole genome sequencing of diffuse large B-cell lymphoma, and could identify mutations in all Teneurin genes (Morin et al., 2013). Interestingly, TENM2 was validated as frequently mutated in this cancer by analyzing data from additional cohorts. Further, TENM2 mutations showed evidence for positive selection, which favored their driver function in tumorigenesis. Two of these mutations were nonsense and predicted the expression of a truncated protein or its degradation, in analogy to the variant observed in microphtalmia (Aldahmesh et al., 2012). However, it should be noted that most Teneurin variants in this report were accompanied by annotation errors and their precise location cannot be deduced. A second study performed whole-exome sequencing of primary lymphomas of the central nervous system (Vater et al., 2015). One missense mutation was found in TENM3, while TENM4 was among the 4 most frequently mutated genes (missense mutations in 4 of 9 tumors). Three mutations mapped to the extracellular domain, of which two lied between YD repeats and one was predicted to affect an EGF-like motif. A fourth mutation affected a potential phosphorylation site within the ICD. These data suggest a potential functional impact for Teneurin mutations, which might contribute to tumorigenesis. The authors further noted that mutations in TENM4 and PIM1 were mutually exclusive. Interestingly, the oncogenic PIM1 serine-threonine kinase is essential for MYC-mediated tumorigenesis in triple-negative breast cancer cells, where knock-out of both genes was synthetic lethal (Horiuchi et al., 2016). Since Teneurin-1 did mediate MYC-RHOA-induced responses in glioblastoma (Talamillo et al., 2017), additional Teneurins might operate through a similar mechanism. Assuming that PIM1 and Teneurins both act through a MYC-dependent pathway, co-selection of mutations might not provide an additional advantage to tumor cells, explaining the lack of concurrent variants in these genes.

\section{The Mutation Profile of Teneurin Genes}

Based on the above data, Teneurins appear to be a frequent target for somatic mutation in lymphomas, and the phenotypic consequence of singe nucleotide changes is evidenced from genetic conditions associated with germline changes. To assess if similar findings apply to other tumors, we performed gene-based searches for all Teneurins in The Cancer Genome Atlas (TCGA, https://cancergenome.nih.gov/). Teneurin mutations recorded for the entire TCGA cohort are represented in Figure 2A, sorted according to their subtype. The mutation spectrum of known oncogenes (AKT1, PIK3CA, BRAF) and tumor suppressor genes (TP53, BRCA1, CDKN2A) is included for comparison. Over 750 variants could be retrieved for each Teneurin gene. As evidenced by the graphs, Teneurin missense changes clearly predominate and their mutation spectra do not resemble those of TP53 or CDKN2A. Nonsense variants were infrequent, in analogy to germline findings in essential tremor patients (Houle et al., 2017). When the mutation subtype frequency was represented in a Euclidean-distance cladogram (Figure 2B), Teneurin genes clustered together and their mutation profiles were closer to that of AKT1. However, the next association level was with BRAF and BRCA1, an oncogene and tumor suppressor gene, respectively. According to this distribution, the mutation spectrum of Teneurins places them closer to oncogenes, but a less frequent tumor suppressive pattern cannot be excluded. Functional assessment will be required to assign a phenotypic impact to each variant, in addition to predictive algorithms of pathogenic potential as those applied for heritable conditions. An open question concerns the presence of frequent synonymous variants in the germline (Houle et al., 2017) and in tumors, assumed to represent genetic polymorphisms with restrained phenotypic effects. However, a recent bioinformatics analysis suggested that oncogenes, but not tumor suppressors, are affected by an excess of synonymous somatic mutations in tumors (Supek et al., 2014). Further, selection of synonymous mutations was gene and tumor-specific and targeted evolutionary conserved residues. The data suggested that synonymous variants could 

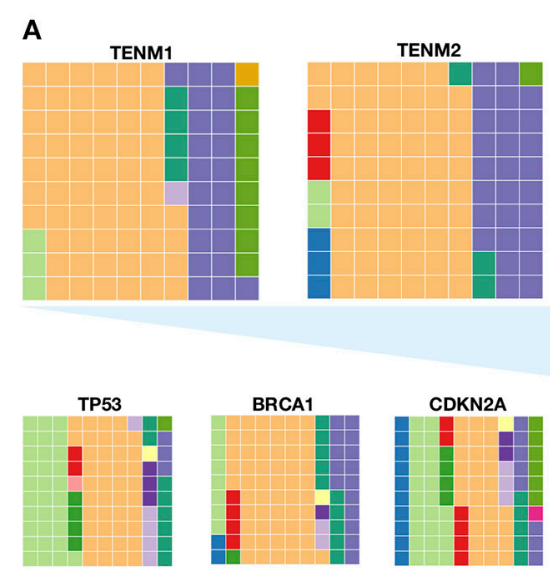

Tumor suppressors
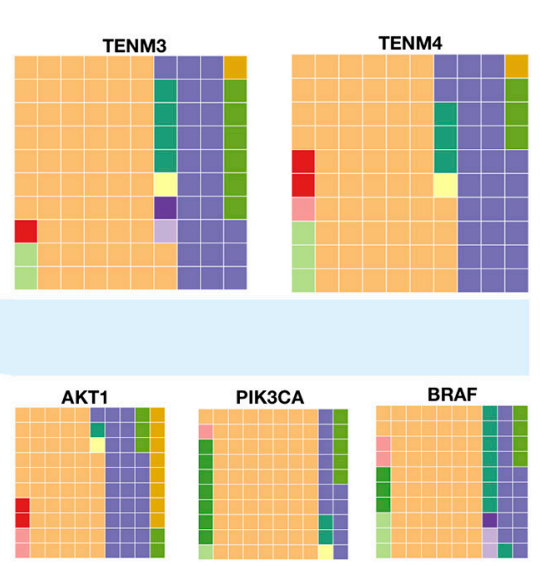

Oncogenes
B
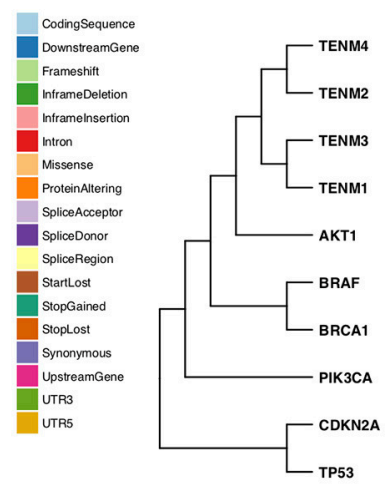

FIGURE 2 | Frequency of mutation types targeting Teneurin genes. All somatic variants reported for Teneurin genes were retrieved from the Caner Genome Atlas, without distinction of tumor type. The number of variants was 1155 for TENM1, 777 for TENM2, 938 for TENM3, and 772 for TENM4. For the remaining genes, variant numbers were 97 for AKT1, 212 for BRAF, 385 for BRCA1, 346 for CDKN2A, 404 for PIK3CA, and 1000 for TP53. (A) Waffle charts describing the proportion of each mutation category. Each square represents a frequency of $1 \%$. Waffle charts at the bottom were calculated from TCGA through the same procedure and are included for comparison. (B) Euclidean-distance cladogram grouping genes based on their mutation type frequency distribution was constructed using the R package hclust.

alter exonic splicing elements, leading to differential exon usage. As reported recurrently, Teneurins are subjected to diverse alternative splicing patterns throughout species (Tucker et al., 2001, 2012; Lossie et al., 2005; Silva et al., 2011; Graumann et al., 2017; Berns et al., 2018; Jackson et al., 2018; Li et al., 2018a), and the sequences that define the splicing system might be altered by missense but also synonymous changes. If applied to Teneurins, the reported results appear to favor an oncogenic role driven by missense and perhaps synonymous single nucleotide mutations.

\section{CONCLUDING REMARKS}

In recent investigations, exciting discoveries have revealed the amazing level of complexity that surrounds the function of Teneurins. These large proteins present different domains enabling a range of biological functions from adhesion to cell signaling. As could be predicted form their evolutionary conservation, genetic changes are demonstrating phenotypic consequences that underlie different heritable conditions. Reviewing the available literature and retrieving information from cancer databases, we could now gather evidence that strongly supports a role of Teneurins in tumorigenesis. Clearly, these genes are affected by tumor-specific changes through mechanisms expected for validated cancer genes, including chromosomal alterations, somatic mutations, and aberrant expression patterns. The inherent function of Teneurins as signaling molecules consistently involves well-established cancer pathways, such as NOTCH, WNT, and the NRG/ERBB axis. Further, their essential function as adherence molecules can alter processes related to cell adhesion, migration and invasion, and impact on cell plasticity by modulating cell differentiation and transition between epithelial and mesenchymal phenotypes. Accordingly, a prognostic association of Teneurin expression with patient survival has been demonstrated for various cancer types. Based on current molecular evidence, it seems highly probable that Teneurins might exhibit an oncogenic contribution to tumor initiation, growth and progression, although a dual function including tumor suppressive roles cannot be excluded at present. A major issue will be the validation of the pathogenic impact of Teneurin somatic changes, which will be challenging considering Teneurin gene lengths, their complex pattern of alternatively spliced species, and their tissue-specific relevance. The number of somatic variants in tumors is large and most seem to occur at low allele frequencies. The rising volume of omics data available through patient-based repositories will indubitably provide an important means to address some of these challenges, and aid to the validation of Teneurins as representative cancer genes.

\section{AUTHOR CONTRIBUTIONS}

AZ performed literature and data searches, retrieved data from repositories, created tables, and wrote the manuscript. BR-J retrieved and analyzed data from repositories, created figures, and critically reviewed the manuscript.

\section{FUNDING}

This work was supported by grant CONICYT FONDEQUIP EQM150093. 


\section{REFERENCES}

Adélaïde, J., Chaffanet, M., Mozziconacci, M. J., Popovici, C., Conte, N., Fernandez, F., et al. (2000). Translocation and coamplification of loci from chromosome arms $8 \mathrm{p}$ and $11 \mathrm{q}$ in the MDA-MB-175 mammary carcinoma cell line. Int. J. Oncol. 16, 683-688. doi: 10.3892/ijo.16.4.683

Afghani, N., Mehta, T., Wang, J., Tang, N., Skalli, O., and Quick, Q. A. (2017). Microtubule actin cross-linking factor 1, a novel target in glioblastoma. Int. J. Oncol. 50, 310-316. doi: 10.3892/ijo.2016.3798

Aldahmesh, M. A., Mohammed, J. Y., Al-Hazzaa, S., and Alkuraya, F. S. (2012). Homozygous null mutation in ODZ3 causes microphthalmia in humans. Genet. Med. 14, 900-904. doi: 10.1038/gim.2012.71

Alkelai, A., Olender, T., Haffner-Krausz, R., Tsoory, M. M., Boyko, V., Tatarskyy, P., et al. (2016). A role for TENM1 mutations in congenital general anosmia. Clin. Genet. 90, 211-219. doi: 10.1111/cge.12782

Arigoni, M., Barutello, G., Riccardo, F., Ercole, E., Cantarella, D., Orso, F., et al. (2013). miR-135b coordinates progression of ErbB2-driven mammary carcinomas through suppression of MID1 and MTCH2. Am. J. Pathol. 182, 2058-2070. doi: 10.1016/j.ajpath.2013.02.046

Bagutti, C., Forro, G., Ferralli, J., Rubin, B., and Chiquet-Ehrismann, R. (2003). The intracellular domain of teneurin-2 has a nuclear function and represses zic-1-mediated transcription. J. Cell. Sci. 116, 2957-2966. doi: 10.1242/jcs.00603

Balogh, G. A., Heulings, R., Mailo, D. A., Russo, P. A., Sheriff, F., Russo, I. H., et al. (2006). Genomic signature induced by pregnancy in the human breast. Int. J. Oncol. 28, 399-410. doi: 10.3892/ijo.28.2.399

Banerji, S., Cibulskis, K., Rangel-Escareno, C., Brown, K. K., Carter, S. L., Frederick, A. M., et al. (2012). Sequence analysis of mutations and translocations across breast cancer subtypes. Nature 486, 405-409. doi: 10.1038/nature11154

Baumgartner, S., Martin, D., Hagios, C., and Chiquet-Ehrismann, R. (1994). Tenm, a Drosophila gene related to tenascin, is a new pair-rule gene. EMBO J. 13, 3728-3740.

Baykara, O., Bakir, B., Buyru, N., Kaynak, K., and Dalay, N. (2015). Amplification of chromosome 8 genes in lung cancer. J. Cancer 6, 270-275. doi: $10.7150 /$ jca. 10638

Beckmann, J., Schubert, R., Chiquet-Ehrismann, R., and Müller, D. J. (2013). Deciphering teneurin domains that facilitate cellular recognition, cell-cell adhesion, and neurite outgrowth using atomic force microscopy-based single-cell force spectroscopy. Nano Lett. 13, 2937-2946. doi: 10.1021/nl40 13248

Beckmann, J., Vitobello, A., Ferralli, J., BroŽ, D. K., Rijli, F. M., and ChiquetEhrismann, R. (2011). Human teneurin-1 is a direct target of the homeobox transcription factor EMX2 at a novel alternate promoter. BMC Dev. Biol. 11:35. doi: 10.1186/1471-213X-11-35

Ben-Zur, T., Feige, E., Motro, B., and Wides, R. (2000). The mammalian Odz gene family: homologs of a Drosophila pair-rule gene with expression implying distinct yet overlapping developmental roles. Dev. Biol. 217, 107-120. doi: 10.1006/dbio.1999.9532

Berns, D. S., DeNardo, L. A., Pederick, D. T., and Luo, L. (2018). Teneurin3 controls topographic circuit assembly in the hippocampus. Nature 554, 328-333. doi: 10.1038/nature25463

Boeva, V., Jouannet, S., Daveau, R., Combaret, V., Pierre-Eugène, C., Cazes, A., et al. (2013). Breakpoint features of genomic rearrangements in neuroblastoma with unbalanced translocations and chromothripsis. PLOS ONE 8:e72182. doi: 10.1371/journal.pone.0072182

Boucard, A. A., Maxeiner, S., and Südhof, T. C. (2014). Latrophilins function as heterophilic cell-adhesion molecules by binding to teneurins: regulation by alternative splicing. J. Biol. Chem. 289, 387-402. doi: 10.1074/jbc.M113.504779

Brennand, K. J., Simone, A., Jou, J., Gelboin-Burkhart, C., Tran, N., Sangar, S., et al. (2011). Modelling schizophrenia using human induced pluripotent stem cells. Nature 473, 221-225. doi: 10.1038/nature09915

Bröhl, D., Vasyutina, E., Czajkowski, M. T., Griger, J., Rassek, C., Rahn, H.-P., et al. (2012). Colonization of the satellite cell niche by skeletal muscle progenitor cells depends on Notch signals. Dev. Cell 23, 469-481. doi: 10.1016/j.devcel.2012.07.014

Buys, T. P. H., Chari, R., Lee, E. H. L., Zhang, M., MacAulay, C., Lam, S., et al. (2007). Genetic changes in the evolution of multidrug resistance for cultured human ovarian cancer cells. Genes Chromosomes Cancer 46, 1069-1079. doi: $10.1002 /$ gcc. 20492
Cancer Genome Atlas Research Network, Ley, T. J., Miller, C., Ding, L., Raphael, B. J., Mungall, A. J., et al. (2013). Genomic and epigenomic landscapes of adult de novo acute myeloid leukemia. N. Engl. J. Med. 368, 2059-2074. doi: 10.1056/NEJMoa1301689

Canela, A., Maman, Y., Jung, S., Wong, N., Callen, E., Day, A., et al. (2017). Genome organization drives chromosome fragility. Cell 170, 507-521.e18. doi: 10.1016/j.cell.2017.06.034

Chand, D., Song, L., deLannoy, L., Barsyte-Lovejoy, D., Ackloo, S., Boutros, P. C., et al. (2012). C-Terminal region of teneurin-1 co-localizes with dystroglycan and modulates cytoskeletal organization through an extracellular signal-regulated kinase-dependent stathmin- and filamin Amediated mechanism in hippocampal cells. Neuroscience 219, 255-270. doi: 10.1016/j.neuroscience.2012.05.069

Chen, H.-J., Lin, C.-M., Lin, C.-S., Perez-Olle, R., Leung, C. L., and Liem, R. K. H. (2006). The role of microtubule actin cross-linking factor 1 (MACF1) in the Wnt signaling pathway. Genes Dev. 20, 1933-1945. doi: 10.1101/gad.14 11206

Cheng, S.-P., Chen, M.-J., Chien, M.-N., Lin, C.-H., Lee, J.-J., and Liu, C.-L. (2016). Overexpression of teneurin transmembrane protein 1 is a potential marker of disease progression in papillary thyroid carcinoma. Clin. Exp. Med. 17:555. doi: 10.1007/s10238-016-0445-y

Choussein, S., Nasioudis, D., Schizas, D., and Economopoulos, K. P. (2017). Mullerian dysgenesis: a critical review of the literature. Arch. Gynecol. Obstet. 295, 1369-1381. doi: 10.1007/s00404-017-4372-2

Cuadros, T., Trilla, E., Sarró, E., Vilà, M. R., Vilardell, J., de Torres, I., et al. (2014). HAVCR/KIM-1 activates the IL-6/STAT-3 pathway in clear cell renal cell carcinoma and determines tumor progression and patient outcome. Cancer Res. 74, 1416-1428. doi: 10.1158/0008-5472.CAN-13-1671

Cui, X., Lu, Z., Kurosawa, A., Klemm, L., Bagshaw, A. T., Tsai, A. G., et al. (2013). Both CpG methylation and activation-induced deaminase are required for the fragility of the human bcl-2 major breakpoint region: implications for the timing of the breaks in the $t(14 ; 18)$ translocation. Mol. Cell. Biol. 33, 947-957. doi: 10.1128/MCB.01436-12

Dall, K. L., Scarpini, C. G., Roberts, I., Winder, D. M., Stanley, M. A., Muralidhar, B., et al. (2008). Characterization of naturally occurring HPV16 integration sites isolated from cervical keratinocytes under noncompetitive conditions. Cancer Res. 68, 8249-8259. doi: 10.1158/0008-5472.CAN-08-1741

De Braekeleer, E., Douet-Guilbert, N., Morel, F., Le Bris, M.-J., Basinko, A., and De Braekeleer, M. (2012). ETV6 fusion genes in hematological malignancies: a review. Leuk. Res. 36, 945-961. doi: 10.1016/j.leukres.2012.04.010

Debatisse, M., Le Tallec, B., Letessier, A., Dutrillaux, B., and Brison, O. (2012). Common fragile sites: mechanisms of instability revisited. Trends Genet. 28, 22-32. doi: 10.1016/j.tig.2011.10.003

Dickreuter, E., and Cordes, N. (2017). The cancer cell adhesion resistome: mechanisms, targeting and translational approaches. Biol. Chem. 398, 721-735. doi: 10.1515/hsz-2016-0326

Ding, L., Shen, Y., Ni, J., Ou, Y., Ou, Y., and Liu, H. (2017). EphA4 promotes cell proliferation and cell adhesion-mediated drug resistance via the AKT pathway in multiple myeloma. Tumour Biol. 39:1010428317694298. doi: $10.1177 / 1010428317694298$

Doolittle-Hall, J. M., Cunningham Glasspoole, D. L., Seaman, W. T., and WebsterCyriaque, J. (2015). Meta-Analysis of DNA Tumor-Viral Integration Site Selection Indicates a Role for Repeats, Gene Expression and Epigenetics. Cancers 7, 2217-2235. doi: 10.3390/cancers7040887

Drabikowski, K., Trzebiatowska, A., and Chiquet-Ehrismann, R. (2005). ten-1, an essential gene for germ cell development, epidermal morphogenesis, gonad migration, and neuronal pathfinding in Caenorhabditis elegans. Dev. Biol. 282, 27-38. doi: 10.1016/j.ydbio.2005.02.017

Fascetti, N., and Baumgartner, S. (2002). Expression of Drosophila Ten-a, a dimeric receptor during embryonic development. Mech. Dev. 114, 197-200. doi: 10.1016/S0925-4773(02)00055-2

Feitelson, M. A., and Lee, J. (2007). Hepatitis B virus integration, fragile sites, and hepatocarcinogenesis. Cancer Lett. 252, 157-170. doi: 10.1016/j.canlet.2006.11.010

Feldman, G. J., Freeman, T., Fertala, A., and Parvizi, J. (2017). A Novel Mutation in the C-Terminal Associated Peptide (TCAP) Region of Teneurin 3 Found to co-Segregate in all Affecteds in a Multi-Generation Family with Developmental Dysplasia of the Hip. Orlando, FL. 
Feng, K., Zhou, X.-H., Oohashi, T., Mörgelin, M., Lustig, A., Hirakawa, S., et al. (2002). All four members of the Ten-m/Odz family of transmembrane proteins form dimers. J. Biol. Chem. 277, 26128-26135. doi: 10.1074/jbc.M203722200

Ferralli, J., Tucker, R. P., and Chiquet-Ehrismann, R. (2018). The teneurin Cterminal domain possesses nuclease activity and is apoptogenic. Biol Open 7:bio031765. doi: 10.1242/bio.031765

Frenkel-Morgenstern, M., Lacroix, V., Ezkurdia, I., Levin, Y., Gabashvili, A., Prilusky, J., et al. (2012). Chimeras taking shape: potential functions of proteins encoded by chimeric RNA transcripts. Genome Res. 22, 1231-1242. doi: $10.1101 /$ gr.130062.111

García-Frigola, C., Carreres, M. I., Vegar, C., Mason, C., and Herrera, E. (2008). Zic2 promotes axonal divergence at the optic chiasm midline by EphB1dependent and -independent mechanisms. Development 135, 1833-1841. doi: $10.1242 /$ dev.020693

George, J., Lim, J. S., Jang, S. J., Cun, Y., Ozretić, L., Kong, G., et al. (2015). Comprehensive genomic profiles of small cell lung cancer. Nature 524, 47-53. doi: $10.1038 /$ nature 14664

Glendining, K. A., Liu, S. C., Nguyen, M., Dharmaratne, N., Nagarajah, R., Iglesias, M. A., et al. (2017). Downstream mediators of Ten-m3 signalling in the developing visual pathway. BMC Neurosci 18:78. doi: $10.1186 /$ s12868-017-0397-5

Glover, T. W., Wilson, T. E., and Arlt, M. F. (2017). Fragile sites in cancer: more than meets the eye. Nat. Rev. Cancer 17, 489-501. doi: 10.1038/nrc.2017.52

Gómez, S., Castellano, G., Mayol, G., Suñol, M., Queiros, A., Bibikova, M., et al. (2015). DNA methylation fingerprint of neuroblastoma reveals new biological and clinical insights. Epigenomics 7, 1137-1153. doi: 10.2217/epi.15.49

Graner, M. W., Bunch, T. A., Baumgartner, S., Kerschen, A., and Brower, D. L. (1998). Splice variants of the Drosophila PS2 integrins differentially interact with RGD-containing fragments of the extracellular proteins tiggrin, ten-m, and D-laminin 2. J. Biol. Chem. 273, 18235-18241.

Graumann, R., Di Capua, G. A., Oyarzún, J. E., Vásquez, M. A., Liao, C., Brañes, J. A., et al. (2017). Expression of teneurins is associated with tumor differentiation and patient survival in ovarian cancer. PLOS ONE 12:e0177244. doi: 10.1371/journal.pone.0177244

Greger, L., Su, J., Rung, J., Ferreira, P. G., Geuvadis consortium, Lappalainen, T., et al. (2014). Tandem RNA chimeras contribute to transcriptome diversity in human population and are associated with intronic genetic variants. PLOS ONE 9:e104567. doi: 10.1371/journal.pone.0104567

Hazan, I., Hofmann, T. G., and Aqeilan, R. I. (2016). Tumor suppressor genes within common fragile sites are active players in the DNA damage response. PLoS Genet 12:e1006436. doi: 10.1371/journal.pgen.1006436

He, F., and Jacobson, A. (2015). Nonsense-Mediated mRNA decay: degradation of defective transcripts is only part of the story. Annu. Rev. Genet. 49, 339-366. doi: 10.1146/annurev-genet-112414-054639

Heining, C., Horak, P., Uhrig, S., Codo, P. L., Klink, B., Hutter, B., et al. (2018). NRG1 Fusions in KRAS Wild-type pancreatic cancer. Cancer Discov. 8, 1087-1095. doi: 10.1158/2159-8290.CD-18-0036

Hollestelle, A., Elstrodt, F., Nagel, J. H. A., Kallemeijn, W. W., and Schutte, M. (2007). Phosphatidylinositol-3-OH kinase or RAS pathway mutations in human breast cancer cell lines. Mol. Cancer Res. 5, 195-201. doi: 10.1158/1541-7786.MCR-06-0263

Hong, W., Mosca, T. J., and Luo, L. (2012). Teneurins instruct synaptic partner matching in an olfactory map. Nature. 484, 201-217. doi: 10.1038/nature10926

Hor, H., Francescatto, L., Bartesaghi, L., Ortega-Cubero, S., Kousi, M., LorenzoBetancor, O., et al. (2015). Missense mutations in TENM4, a regulator of axon guidance and central myelination, cause essential tremor. Hum. Mol. Genet. 24, 5677-5686. doi: 10.1093/hmg/ddv281

Horiuchi, D., Camarda, R., Zhou, A. Y., Yau, C., Momcilovic, O., Balakrishnan, S., et al. (2016). PIM1 kinase inhibition as a targeted therapy against triple-negative breast tumors with elevated MYC expression. Nat. Med. 22, 1321-1329. doi: $10.1038 / \mathrm{nm} .4213$

Houle, G., Schmouth, J.-F., Leblond, C. S., Ambalavanan, A., Spiegelman, D., Laurent, S. B., et al. (2017). Teneurin transmembrane protein 4 is not a cause for essential tremor in a Canadian population. Mov. Disord. 32, 292-295. doi: $10.1002 / \mathrm{mds} .26753$

Houtmeyers, R., Souopgui, J., and Tejpar, S. (2018). Deregulation of ZIC Family Members in Oncogenesis. Adv. Exp. Med. Biol. 1046, 329-338. doi: 10.1007/978-981-10-7311-3_16
Huang, X., Zhu, H., Gao, Z., Li, J., Zhuang, J., Dong, Y., et al. (2018). Wnt7a activates canonical Wnt signaling, promotes bladder cancer cell invasion, and is suppressed by miR-370-3p. J. Biol. Chem. 293, 6693-6706. doi: 10.1074/jbc.RA118.001689

Hughes-Davies, L., Huntsman, D., Ruas, M., Fuks, F., Bye, J., Chin, S.-F., et al. (2003). EMSY links the BRCA2 pathway to sporadic breast and ovarian cancer. Cell 115, 523-535. doi: 10.1016/S0092-8674(03)00930-9

Huret, J.-L., Ahmad, M., Arsaban, M., Bernheim, A., Cigna, J., Desangles, F., et al. (2013). Atlas of genetics and cytogenetics in oncology and haematology in 2013. Nucleic Acids Res. 41, D920-D924. doi: 10.1093/nar/gks1082

Hynes, N. E. (2016). ErbB2: From an EGFR relative to a central target for cancer therapy. Cancer Res 76, 3659-3662. doi: 10.1158/0008-5472.CAN-16-1356

Inaki, K., Hillmer, A. M., Ukil, L., Yao, F., Woo, X. Y., Vardy, L. A., et al. (2011). Transcriptional consequences of genomic structural aberrations in breast cancer. Genome Res. 21, 676-687. doi: 10.1101/gr.1132 25.110

Ishii, K., Suzuki, N., Mabuchi, Y., Ito, N., Kikura, N., Fukada, S.-I., et al. (2015). Muscle satellite cell protein teneurin-4 regulates differentiation during muscle regeneration. Stem Cells 33, 3017-3027. doi: 10.1002/stem.2058

Ivorra, J. L., Rivero, O., Costas, J., Iniesta, R., Arrojo, M., Ramos-Ríos, R., et al. (2014). Replication of previous genome-wide association studies of psychiatric diseases in a large schizophrenia case-control sample from Spain. Schizophr. Res. 159, 107-113. doi: 10.1016/j.schres.2014.07.004

Iwakawa, R., Takenaka, M., Kohno, T., Shimada, Y., Totoki, Y., Shibata, T., et al. (2013). Genome-wide identification of genes with amplification and/or fusion in small cell lung cancer. Genes Chromosomes Cancer 52, 802-816. doi: $10.1002 / \mathrm{gcc} .22076$

Jackson, V. A., Meijer, D. H., Carrasquero, M., van Bezouwen, L. S., Lowe, E. D., Kleanthous, C., et al. (2018). Structures of Teneurin adhesion receptors reveal an ancient fold for cell-cell interaction. Nat Commun 9:1079. doi: 10.1038/s41467-018-03460-0

Jang, M. K., Shen, K., and McBride, A. A. (2014). Papillomavirus genomes associate with BRD4 to replicate at fragile sites in the host genome. PLoS Pathog. 10:e1004117. doi: 10.1371/journal.ppat.1004117

Jansen, M. P. H. M., Foekens, J. A., van Staveren, I. L., Dirkzwager-Kiel, M. M., Ritstier, K., Look, M. P., et al. (2005). Molecular classification of tamoxifenresistant breast carcinomas by gene expression profiling. J. Clin. Oncol. 23, 732-740. doi: 10.1200/JCO.2005.05.145

Jiang, Z., Jhunjhunwala, S., Liu, J., Haverty, P. M., Kennemer, M. I., Guan, Y., et al. (2012). The effects of hepatitis B virus integration into the genomes of hepatocellular carcinoma patients. Genome Res. 22, 593-601. doi: $10.1101 /$ gr.133926.111

Karras, J. R., Schrock, M. S., Batar, B., and Huebner, K. (2016). Fragile genes that are frequently altered in cancer: players not passengers. Cytogenet. Genome Res. 150, 208-216. doi: 10.1159/000455753

Kenzelmann-Broz, D., Tucker, R. P., Leachman, N. T., and Chiquet-Ehrismann, R. (2010). The expression of teneurin-4 in the avian embryo: potential roles in patterning of the limb and nervous system. Int. J. Dev. Biol. 54, 1509-1516. doi: $10.1387 / \mathrm{ijdb} .103139 \mathrm{dk}$

Kim, J.-Y., Jung, H. H., Do, I.-G., Bae, S., Lee, S. K., Kim, S. W., et al. (2016). Prognostic value of ERBB4 expression in patients with triple negative breast cancer. BMC Cancer 16:138. doi: 10.1186/s12885-016-2195-3

Knight, J. F., Sung, V. Y. C., Kuzmin, E., Couzens, A. L., de Verteuil, D. A., Ratcliffe, C. D. H., et al. (2018). KIBRA (WWC1) Is a Metastasis Suppressor Gene Affected by Chromosome 5q Loss in triple-negative breast cancer. Cell Rep. 22, 3191-3205. doi: 10.1016/j.celrep.2018.02.095

Ko, C.-J., Huang, C.-C., Lin, H.-Y., Juan, C.-P., Lan, S.-W., Shyu, H.Y., et al. (2015). Androgen-Induced TMPRSS2 activates matriptase and promotes extracellular matrix degradation, prostate cancer cell invasion, tumor growth, and metastasis. Cancer Res. 75, 2949-2960. doi: 10.1158/0008-5472.CAN-14-3297

Kolev, V. N., Tam, W. F., Wright, Q. G., McDermott, S. P., Vidal, C. M., Shapiro, I. M., et al. (2017). Inhibition of FAK kinase activity preferentially targets cancer stem cells. Oncotarget 8, 51733-51747. doi: 10.18632/oncotarget. 18517

Kou, C.-T. J., and Kandpal, R. P. (2018). Differential expression patterns of Eph receptors and ephrin ligands in human cancers. Biomed Res Int. 2018:7390104. doi: $10.1155 / 2018 / 7390104$ 
Kumar, R., Nagpal, G., Kumar, V., Usmani, S. S., Agrawal, P., and Raghava, G. P. S. (2017). HumCFS: a database of fragile sites in human chromosomes. bioRxiv [preprint] 231233. doi: 10.1101/231233

Leamey, C. A., Merlin, S., Lattouf, P., Sawatari, A., Zhou, X., Demel, N., et al. (2007). Ten_m3 regulates eye-specific patterning in the mammalian visual pathway and is required for binocular vision. PLoS Biol. 5:e241. doi: 10.1371/journal.pbio.0050241

Lee, M., Lee, K., Yu, N., Jang, I., Choi, I., Kim, P., et al. (2017). ChimerDB 3.0: an enhanced database for fusion genes from cancer transcriptome and literature data mining. Nucleic Acids Res. 45, D784-D789. doi: 10.1093/nar/gkw1083

Lee, S., Medina, D., Tsimelzon, A., Mohsin, S. K., Mao, S., Wu, Y., et al. (2007). Alterations of gene expression in the development of early hyperplastic precursors of breast cancer. Am. J. Pathol. 171, 252-262. doi: 10.2353 /ajpath.2007.061010

Lee, Y., Lee, J.-K., Ahn, S. H., Lee, J., and Nam, D.-H. (2016). WNT signaling in glioblastoma and therapeutic opportunities. Lab. Invest. 96, 137-150. doi: $10.1038 /$ labinvest.2015.140

Lee-Hoeflich, S. T., Crocker, L., Yao, E., Pham, T., Munroe, X., Hoeflich, K. P., et al. (2008). A central role for HER3 in HER2-amplified breast cancer: implications for targeted therapy. Cancer Res. 68, 5878-5887. doi: 10.1158/0008-5472.CAN-08-0380

Levine, A., Bashan-Ahrend, A., Budai-Hadrian, O., Gartenberg, D., Menasherow, S., and Wides, R. (1994). Odd Oz: a novel Drosophila pair rule gene. Cell 77, 587-598.

Li, J., Shalev-Benami, M., Sando, R., Jiang, X., Kibrom, A., Wang, J., et al. (2018a). Structural basis for teneurin function in circuit-wiring: a toxin motif at the synapse. Cell 173, 735-748.e15. doi: 10.1016/j.cell.2018.03.036

Li, L., Chen, B.-F., and Chan, W.-Y. (2015). An epigenetic regulator: methylCpG-binding domain protein 1 (MBD1). Int. J. Mol. Sci. 16, 5125-5140. doi: $10.3390 /$ ijms 16035125

Li, L., Xu, J., Qiu, G., Ying, J., Du, Z., Xiang, T., et al. (2018b). Epigenomic characterization of a p53-regulated 3p22.2 tumor suppressor that inhibits STAT3 phosphorylation via protein docking and is frequently methylated in esophageal and other carcinomas. Theranostics 8, 61-77. doi: 10.7150/thno.20893

Lin, J.-C., Lee, Y.-C., Tan, T.-H., Liang, Y.-C., Chuang, H.-C., Fann, Y. C., et al. (2018). RBM4-SRSF3-MAP4K4 splicing cascade modulates the metastatic signature of colorectal cancer cell. Biochim. Biophys. Acta 1865, 259-272. doi: 10.1016/j.bbamcr.2017.11.005

Liu, X., Baker, E., Eyre, H. J., Sutherland, G. R., and Zhou, M. (1999). Gamma-heregulin: a fusion gene of DOC-4 and neuregulin-1 derived from a chromosome translocation. Oncogene 18, 7110-7114. doi: 10.1038/sj.onc. 1203136

Lossie, A. C., Nakamura, H., Thomas, S. E., and Justice, M. J. (2005). Mutation of $17 \mathrm{Rn} 3$ Shows That Odz4 Is required for mouse gastrulation. Genetics 169, 285-299. doi: 10.1534/genetics.104.034967

Lu, Z., Lieber, M. R., Tsai, A. G., Pardo, C. E., Müschen, M., Kladde, M. P., et al. (2015). Human lymphoid translocation fragile zones are hypomethylated and have accessible chromatin. Mol. Cell. Biol. 35, 1209-1222. doi: 10.1128/MCB.01085-14

Martincorena, I., Raine, K. M., Gerstung, M., Dawson, K. J., Haase, K., Van Loo, P., et al. (2017). Universal patterns of selection in cancer and somatic tissues. Cell 171, 1029-1041.e21. doi: 10.1016/j.cell.2017.09.042

Maturi, V., Enroth, S., Heldin, C., and Moustakas, A. (2018). Genome-wide binding of transcription factor ZEB1 in triple-negative breast cancer cells. J. Cell Physiol. 233, 7113-7127. doi: 10.1002/jcp.26634

Mei, L., and Nave, K.-A. (2014). Neuregulin-ERBB signaling in the nervous system and neuropsychiatric diseases. Neuron 83, 27-49. doi: 10.1016/j.neuron.2014.06.007

Merlin, S., Horng, S., Marotte, L. R., Sur, M., Sawatari, A., and Leamey, C. A. (2013). Deletion of Ten-m3 induces the formation of eye dominance domains in mouse visual cortex. Cereb. Cortex 23, 763-774. doi: 10.1093/cercor/bhs030

Mertens, F., Johansson, B., Fioretos, T., and Mitelman, F. (2015). The emerging complexity of gene fusions in cancer. Nat. Rev. Cancer 15, 371-381. doi: $10.1038 / \mathrm{nrc} 3947$

Miller, C., and Sassoon, D. A. (1998). Wnt-7a maintains appropriate uterine patterning during the development of the mouse female reproductive tract. Development 125, 3201-3211.
Minami, M., Daimon, Y., Mori, K., Takashima, H., Nakajima, T., Itoh, Y., et al. (2005). Hepatitis B virus-related insertional mutagenesis in chronic hepatitis $B$ patients as an early drastic genetic change leading to hepatocarcinogenesis. Oncogene 24, 4340-4348. doi: 10.1038/sj.onc. 1208628

Minet, A. D., and Chiquet-Ehrismann, R. (2000). Phylogenetic analysis of teneurin genes and comparison to the rearrangement hot spot elements of E. coli. Gene 257, 87-97. doi: 10.1016/S0378-1119(00)00388-7

Minet, A. D., Rubin, B. P., Tucker, R. P., Baumgartner, S., and Chiquet-Ehrismann, R. (1999). Teneurin-1, a vertebrate homologue of the Drosophila pair-rule gene ten-m, is a neuronal protein with a novel type of heparin-binding domain. $J$. Cell. Sci. 112 ( Pt 12), 2019-2032.

Mitelman, F., Johansson, B., and Mertens, F. (2007). The impact of translocations and gene fusions on cancer causation. Nat. Rev. Cancer 7, 233-245. doi: $10.1038 / \mathrm{nrc} 2091$

Molenaar, J. J., Koster, J., Zwijnenburg, D. A., van Sluis, P., Valentijn, L. J., van der Ploeg, I., et al. (2012). Sequencing of neuroblastoma identifies chromothripsis and defects in neuritogenesis genes. Nature 483, 589-593. doi: 10.1038/nature10910

Mörck, C., Vivekanand, V., Jafari, G., and Pilon, M. (2010). C. elegans ten-1 is synthetic lethal with mutations in cytoskeleton regulators, and enhances many axon guidance defective mutants. BMC Dev. Biol. 10:55. doi: 10.1186/1471-213X-10-55

Morin, R. D., Mungall, K., Pleasance, E., Mungall, A. J., Goya, R., Huff, R. D., et al. (2013). Mutational and structural analysis of diffuse large B-cell lymphoma using whole-genome sequencing. Blood 122, 1256-1265. doi: 10.1182/blood-2013-02-483727

Mosca, T. J., Hong, W., Dani, V. S., Favaloro, V., and Luo, L. (2012). Trans-synaptic Teneurin signalling in neuromuscular synapse organization and target choice. Nature 484, 237-241 doi: 10.1038/nature10923

Murgan, S., Kari, W., Rothbächer, U., Iché-Torres, M., Mélénec, P., Hobert, O., et al. (2015). Atypical Transcriptional Activation by TCF via a Zic Transcription Factor in C. elegans. Neuronal Precursors. Dev. Cell 33, 737-745. doi: 10.1016/j.devcel.2015.04.018

Nakaya, N., Sultana, A., Munasinghe, J., Cheng, A., Mattson, M. P., and Tomarev, S. I. (2013). Deletion in the N-terminal half of olfactomedin 1 modifies its interaction with synaptic proteins and causes brain dystrophy and abnormal behavior in mice. Exp. Neurol. 250, 205-218. doi: 10.1016/j.expneurol.2013.09.019

Nik-Zainal, S., Davies, H., Staaf, J., Ramakrishna, M., Glodzik, D., Zou, X., et al. (2016). Landscape of somatic mutations in 560 breast cancer whole-genome sequences. Nature 534, 47-54. doi: 10.1038/nature17676

Noordhuis, M. G., Fehrmann, R. S. N., Wisman, G. B. A., Nijhuis, E. R., van Zanden, J. J., Moerland, P. D., et al. (2011). Involvement of the TGF-beta and beta-catenin pathways in pelvic lymph node metastasis in early-stage cervical cancer. Clin. Cancer Res. 17, 1317-1330. doi: 10.1158/1078-0432.CCR-102320

Nowell, C. S., and Radtke, F. (2017). Notch as a tumour suppressor. Nat. Rev. Cancer 17, 145-159. doi: 10.1038/nrc.2016.145

Nunes, S. M., Ferralli, J., Choi, K., Brown-Luedi, M., Minet, A. D., and Chiquet-Ehrismann, R. (2005). The intracellular domain of teneurin-1 interacts with MBD1 and CAP/ponsin resulting in subcellular codistribution and translocation to the nuclear matrix. Exp. Cell Res. 305, 122-132. doi: 10.1016/j.yexcr.2004.12.020

Oohashi, T., Zhou, X. H., Feng, K., Richter, B., Mörgelin, M., Perez, M. T., et al. (1999). Mouse ten-m/Odz is a new family of dimeric type II transmembrane proteins expressed in many tissues. J. Cell Biol. 145, 563-577.

Peralta-Arrieta, I., Hernández-Sotelo, D., Castro-Coronel, Y., Leyva-Vázquez, M. A., and Illades-Aguiar, B. (2017). DNMT3B modulates the expression of cancer-related genes and downregulates the expression of the gene VAV3 via methylation. Am J Cancer Res. 7, 77-87.

Petrini, I., Rajan, A., Pham, T., Voeller, D., Davis, S., Gao, J., et al. (2013). Whole Genome and Transcriptome Sequencing of a B3 Thymoma. PLoS ONE 8:e60572. doi: 10.1371/journal.pone.0060572

Plantureux, L., Crescence, L., Dignat-George, F., Panicot-Dubois, L., and Dubois, C. (2018). Effects of platelets on cancer progression. Thromb. Res. 164 (Suppl. 1), S40-S47. doi: 10.1016/j.thromres.2018.01.035

Psychiatric GWAS and Consortium Bipolar Disorder Working Group (2011). Large-scale genome-wide association analysis of bipolar disorder 
identifies a new susceptibility locus near ODZ4. Nat. Genet. 43, 977-983. doi: 10.1038/ng.943

Puente, X. S., Beà, S., Valdés-Mas, R., Villamor, N., Gutiérrez-Abril, J., MartínSubero, J. I., et al. (2015). Non-coding recurrent mutations in chronic lymphocytic leukaemia. Nature 526, 519-524. doi: 10.1038/nature14666

Pugh, T. J., Morozova, O., Attiyeh, E. F., Asgharzadeh, S., Wei, J. S., Auclair, D., et al. (2013). The genetic landscape of high-risk neuroblastoma. Nat. Genet. 45, 279-284. doi: $10.1038 / \mathrm{ng} .2529$

Rodriguez-Perales, S., Torres-Ruiz, R., Suela, J., Acquadro, F., Martin, M. C., Yebra, E., et al. (2016). Truncated RUNX1 protein generated by a novel $\mathrm{t}(1 ; 21)(\mathrm{p} 32 ; \mathrm{q} 22)$ chromosomal translocation impairs the proliferation and differentiation of human hematopoietic progenitors. Oncogene 35, 125-134. doi: $10.1038 /$ onc. 2015.70

Roskoski, R. (2014). The ErbB/HER family of protein-tyrosine kinases and cancer. Pharmacol. Res. 79, 34-74. doi: 10.1016/j.phrs.2013.11.002

Rubin, B. P., Tucker, R. P., Brown-Luedi, M., Martin, D., and Chiquet-Ehrismann, R. (2002). Teneurin 2 is expressed by the neurons of the thalamofugal visual system in situ and promotes homophilic cell-cell adhesion in vitro. Development 129, 4697-4705.

Rubin, B. P., Tucker, R. P., Martin, D., and Chiquet-Ehrismann, R. (1999). Teneurins: a novel family of neuronal cell surface proteins in vertebrates, homologous to the Drosophila pair-rule gene product Ten-m. Dev. Biol. 216, 195-209. doi: 10.1006/dbio.1999.9503

Sadok, A., and Marshall, C. J. (2014). Rho GTPases: masters of cell migration. Small GTPases 5:e29710. doi: 10.4161/sgtp.29710

Sánchez-Valdivieso, E. A., Cruz, J. J., Salazar, R., del Mar Abad, M., Gómez-Alonso, A., Gómez, A., et al. (2002). Gamma-heregulin has no biological significance in primary breast cancer. Br. J. Cancer 86, 1362-1363. doi: 10.1038/sj.bjc.66 00245

Schackmann, R. C. J., Tenhagen, M., van de Ven, R. A. H., and Derksen, P. W. B. (2013). p120-catenin in cancer - mechanisms, models and opportunities for intervention. J. Cell. Sci. 126, 3515-3525. doi: 10.1242/jcs.134411

Schaefer, G., Fitzpatrick, V. D., and Sliwkowski, M. X. (1997). Gammaheregulin: a novel heregulin isoform that is an autocrine growth factor for the human breast cancer cell line, MDA-MB-175. Oncogene 15, 1385-1394. doi: 10.1038/si.onc. 1201317

Schöler, J., Ferralli, J., Thiry, S., and Chiquet-Ehrismann, R. (2015). The intracellular domain of teneurin-1 induces the activity of microphthalmiaassociated transcription factor (MITF) by binding to transcriptional repressor HINT1. J. Biol. Chem. 290, 8154-8165. doi: 10.1074/jbc.M114.615922

Silva, J.-P., Lelianova, V. G., Ermolyuk, Y. S., Vysokov, N., Hitchen, P. G., Berninghausen, O., et al. (2011). Latrophilin 1 and its endogenous ligand Lasso/teneurin-2 form a high-affinity transsynaptic receptor pair with signaling capabilities. Proc. Natl. Acad. Sci. U.S.A. 108, 12113-12118. doi: $10.1073 /$ pnas. 1019434108

Sircoulomb, F., Bekhouche, I., Finetti, P., Adélaïde, J., Ben Hamida, A., Bonansea, J., et al. (2010). Genome profiling of ERBB2-amplified breast cancers. BMC Cancer 10:539. doi: 10.1186/1471-2407-10-539

Smith, D. I., Zhu, Y., McAvoy, S., and Kuhn, R. (2006). Common fragile sites, extremely large genes, neural development and cancer. Cancer Lett. 232, 48-57. doi: 10.1016/j.canlet.2005.06.049

Stewart, D. J. (2014). Wnt signaling pathway in non-small cell lung cancer. J. Natl. Cancer Inst. 106:djt356. doi: 10.1093/jnci/djt356

Supek, F., Miñana, B., Valcárcel, J., Gabaldón, T., and Lehner, B. (2014). Synonymous mutations frequently act as driver mutations in human cancers. Cell 156, 1324-1335. doi: 10.1016/j.cell.2014.01.051

Suzuki, N., Fukushi, M., Kosaki, K., Doyle, A. D., de Vega, S., Yoshizaki, K., et al. (2012). Teneurin-4 is a novel regulator of oligodendrocyte differentiation and myelination of small-diameter axons in the CNS. J. Neurosci. 32, 11586-11599. doi: 10.1523/JNEUROSCI.2045-11.2012

Suzuki, N., Mizuniwa, C., Ishii, K., Nakagawa, Y., Tsuji, K., Muneta, T., et al. (2014a). Teneurin-4, a transmembrane protein, is a novel regulator that suppresses chondrogenic differentiation. J. Orthop. Res. 32, 915-922. doi: 10.1002/jor.22616

Suzuki, N., Numakawa, T., Chou, J., de Vega, S., Mizuniwa, C., Sekimoto, K., et al. (2014b). Teneurin-4 promotes cellular protrusion formation and neurite outgrowth through focal adhesion kinase signaling. FASEB J. 28, 1386-1397. doi: $10.1096 /$ fj.13-241034
Talamillo, A., Grande, L., Ruiz-Ontañon, P., Velasquez, C., Mollinedo, P., Torices, S., et al. (2017). ODZ1 allows glioblastoma to sustain invasiveness through a Myc-dependent transcriptional upregulation of RhoA. Oncogene 36, 1733-1744. doi: 10.1038/onc.2016.341

Taylor, H. S., and Fei, X. (2005). Emx2 regulates mammalian reproduction by altering endometrial cell proliferation. Mol. Endocrinol. 19, 2839-2846. doi: 10.1210/me.2005-0130

Tews, D., Fromme, T., Keuper, M., Hofmann, S. M., Debatin, K. M., Klingenspor, M., et al. (2017). Teneurin-2 (TENM2) deficiency induces UCP1 expression in differentiating human fat cells. Mol. Cell. Endocrinol. 443, 106-113. doi: 10.1016/j.mce.2017.01.015

Tomasovic, A., Kurrle, N., Banning, A., and Tikkanen, R. (2012). Role of Cbl-associated protein/ponsin in receptor tyrosine kinase signaling and cell adhesion. J. Mol. Biochem. 1. 171-182. Available online at: http://jmolbiochem. com/index.php/JmolBiochem/article/view/60/35

Tommasi, S., Karm, D. L., Wu, X., Yen, Y., and Pfeifer, G. P. (2009). Methylation of homeobox genes is a frequent and early epigenetic event in breast cancer. Breast Cancer Res. 11:R14. doi: 10.1186/ bcr2233

Topf, U., and Chiquet-Ehrismann, R. (2011). Genetic interaction between Caenorhabditis elegans teneurin ten-1 and prolyl 4-hydroxylase phy-1 and their function in collagen IV-mediated basement membrane integrity during late elongation of the embryo. Mol. Biol. Cell 22, 3331-3343. doi: 10.1091/mbc.E10-10-0853

Trzebiatowska, A., Topf, U., Sauder, U., Drabikowski, K., and Chiquet-Ehrismann, R. (2008). Caenorhabditis elegans teneurin, ten-1, is required for gonadal and pharyngeal basement membrane integrity and acts redundantly with integrin ina-1 and dystroglycan dgn-1. Mol. Biol. Cell 19, 3898-3908. doi: 10.1091/mbc.E08-01-0028

Tucker, R. P., Beckmann, J., Leachman, N. T., Schöler, J., and ChiquetEhrismann, R. (2012). Phylogenetic analysis of the teneurins: conserved features and premetazoan ancestry. Mol. Biol. Evol. 29, 1019-1029. doi: $10.1093 / \mathrm{molbev} / \mathrm{msr} 271$

Tucker, R. P., and Chiquet-Ehrismann, R. (2006). Teneurins: a conserved family of transmembrane proteins involved in intercellular signaling during development. Dev. Biol. 290, 237-245. doi: 10.1016/j.ydbio.2005.11.038

Tucker, R. P., Chiquet-Ehrismann, R., Chevron, M. P., Martin, D., Hall, R. J., and Rubin, B. P. (2001). Teneurin-2 is expressed in tissues that regulate limb and somite pattern formation and is induced Iand in situ by FGF8. Dev. Dyn. 220, 27-39. doi: 10.1002/1097-0177(2000)9999:9999<::AID-DVDY1084>3.0 $\mathrm{CO} ; 2-\mathrm{B}$

Tucker, R. P., Kenzelmann, D., Trzebiatowska, A., and Chiquet-Ehrismann, R. (2007). Teneurins: transmembrane proteins with fundamental roles in development. Int. J. Biochem. Cell Biol. 39, 292-297. doi: 10.1016/j.biocel.2006.09.012

Vater, I., Montesinos-Rongen, M., Schlesner, M., Haake, A., Purschke, F., Sprute, R., et al. (2015). The mutational pattern of primary lymphoma of the central nervous system determined by whole-exome sequencing. Leukemia 29 , 677-685. doi: 10.1038/leu.2014.264

Vinatzer, U., Gollinger, M., Müllauer, L., Raderer, M., Chott, A., and Streubel, B. (2008). Mucosa-associated lymphoid tissue lymphoma: novel translocations including rearrangements of ODZ2, JMJD2C, and CNN3. Clin. Cancer Res. 14, 6426-6431. doi: 10.1158/1078-0432.CCR-08-0702

Vysokov, N. V., Silva, J.-P., Lelianova, V. G., Ho, C., Djamgoz, M. B., Tonevitsky, A. G., et al. (2016). The Mechanism of Regulated Release of Lasso/Teneurin-2. Front. Mol. Neurosci. 9:59. doi: 10.3389/fnmol.2016.00059

Walther, C., Mayrhofer, M., Nilsson, J., Hofvander, J., Jonson, T., Mandahl, N., et al. (2016). Genetic heterogeneity in rhabdomyosarcoma revealed by SNP array analysis. Genes Chromosomes Cancer 55, 3-15. doi: 10.1002/gcc.22285

Wang, H., Zou, L., Ma, K., Yu, J., Wu, H., Wei, M., et al. (2017). Cell-specific mechanisms of TMEM16A Ca2+-activated chloride channel in cancer. Mol Cancer 16:152 doi: 10.1186/s12943-017-0720-x

Wang, L., Rotzinger, S., Al Chawaf, A., Elias, C. F., Barsyte-Lovejoy, D., Qian, X., et al. (2005). Teneurin proteins possess a carboxy terminal sequence with neuromodulatory activity. Brain Res. Mol. Brain Res. 133, 253-265. doi: 10.1016/j.molbrainres.2004.10.019

Wang, V. W., Laborde, R. R., Asmann, Y. W., Li, Y., Ma, J., Eckloff, B. W., et al. (2013). Search for chromosome rearrangements: new approaches toward 
discovery of novel translocations in head and neck squamous cell carcinoma. Head Neck 35, 831-835. doi: 10.1002/hed.23037

Wang, X., Wang, T.-T., White, J., and Studzinski, G. (2006). Induction of kinase suppressor of RAS-1(KSR-1) gene by1, a25-dihydroxyvitamin D3 in human leukemia HL60 cells through a vitamin D response element in the $5^{\prime}$-flanking region. Oncogene 25, 7078-7085. doi: 10.1038/sj.onc. 1209697

Wang, X. Z., Jolicoeur, E. M., Conte, N., Chaffanet, M., Zhang, Y., Mozziconacci, M. J., et al. (1999). gamma-heregulin is the product of a chromosomal translocation fusing the DOC4 and HGL/NRG1 genes in the MDA-MB175 breast cancer cell line. Oncogene 18, 5718-5721. doi: 10.1038/sj.onc.12 02950

Wang, X. Z., Kuroda, M., Sok, J., Batchvarova, N., Kimmel, R., Chung, P., et al. (1998). Identification of novel stress-induced genes downstream of chop. EMBO J. 17, 3619-3630. doi: 10.1093/emboj/17.13.3619

Wang, Y., Chen, D., Qian, H., Tsai, Y. S., Shao, S., Liu, Q., et al. (2014). The splicing factor RBM4 controls apoptosis, proliferation, and migration to suppress tumor progression. Cancer Cell 26, 374-389. doi: 10.1016/j.ccr.2014.07.010

Wilson, T. E., Arlt, M. F., Park, S. H., Rajendran, S., Paulsen, M., Ljungman, M., et al. (2015). Large transcription units unify copy number variants and common fragile sites arising under replication stress. Genome Res. 25, 189-200. doi: 10.1101 /gr.177121.114

Wright, B., Stanley, R. G., Kaiser, W. J., Mills, D. J., and Gibbins, J. M. (2011). Analysis of protein networks in resting and collagen receptor (GPVI)-stimulated platelet sub-proteomes. Proteomics 11, 4588-4592. doi: 10.1002/pmic.201100410

Xia, D., Le, L. P., Iafrate, A. J., and Lennerz, J. (2017). KIF13B-NRG1 Gene Fusion and KRAS Amplification in a Case of Natural Progression of Lung Cancer. Int. J. Surg. Pathol. 25, 238-240. doi: 10.1177/1066896917693092

Yamada, K. H., Kang, H., and Malik, A. B. (2017). Antiangiogenic Therapeutic potential of peptides derived from the molecular motor KIF13B that transports VEGFR2 to plasmalemma in endothelial cells. Am. J. Pathol. 187, 214-224. doi: 10.1016/j.ajpath.2016.09.010

Yoshihara, K., Wang, Q., Torres-Garcia, W., Zheng, S., Vegesna, R., Kim, H., et al. (2015). The landscape and therapeutic relevance of cancer-associated transcript fusions. Oncogene 34, 4845-4854. doi: 10.1038/onc.2014.406

Young, T. R., Bourke, M., Zhou, X., Oohashi, T., Sawatari, A., Fässler, R., et al. (2013). Ten-m2 is required for the generation of binocular visual circuits. J. Neurosci. 33, 12490-12509. doi: 10.1523/JNEUROSCI.4708-12. 2013

Yu, K., Ganesan, K., Tan, L. K., Laban, M., Wu, J., Zhao, X. D., et al. (2008). A precisely regulated gene expression cassette potently modulates metastasis and survival in multiple solid cancers. PLoS Genet 4:e1000129. doi: 10.1371/journal.pgen.1000129

Zaoui, K., Benseddik, K., Daou, P., Salaün, D., and Badache, A. (2010). ErbB2 receptor controls microtubule capture by recruiting ACF7 to the plasma membrane of migrating cells. Proc. Natl. Acad. Sci. U.S.A. 107, 18517-18522. doi: 10.1073/pnas.1000975107

Zhang, W., Zang, Z., Song, Y., Yang, H., and Yin, Q. (2014). Co-expression network analysis of differentially expressed genes associated with metastasis in prolactin pituitary tumors. Mol. Med. Rep. 10, 113-118. doi: 10.3892/mmr.2014.2152

Zhao, L., Zhou, Z., Wang, S., Jiao, Q., Wu, J., Ma, F., et al. (2017). A recurrent mutation in bone morphogenetic proteins-2inducible kinase gene is associated with developmental dysplasia of the hip. Exp. Ther. Med. 13, 1773-1778. doi: 10.3892/etm.201 7.4191

Zhao, L.-H., Liu, X., Yan, H.-X., Li, W.-Y., Zeng, X., Yang, Y., et al. (2016). Genomic and oncogenic preference of HBV integration in hepatocellular carcinoma. Nat. Commun. 7:12992. doi: 10.1038/ncomms12992

Zheng, J. (2013). Oncogenic chromosomal translocations and human cancer (Review). Oncol. Rep. 30, 2011-2019. doi: 10.3892/or.2013.2677

Zheng, L., Michelson, Y., Freger, V., Avraham, Z., Venken, K. J. T., Bellen, H. J., et al. (2011). Drosophila Ten-m and filamin affect motor neuron growth cone guidance. PLoS ONE 6:e22956. doi: 10.1371/journal.pone.0022956

Zhu, Y., Luo, M., Huang, H., Du, X., Chen, D., Xing, Q., et al. (2016). HOXA10, EMX2 and TENM1 expression in the mid-secretory endometrium of infertile women with a Müllerian duct anomaly. Reprod. Biomed. Online 32, 388-393. doi: 10.1016/j.rbmo.2016.01.005

Ziegler, A., Corvalán, A., Roa, I., Brañes, J. A., and Wollscheid, B. (2012). Teneurin protein family: an emerging role in human tumorigenesis and drug resistance. Cancer Lett. 326, 1-7. doi: 10.1016/j.canlet.2012.07.021

Conflict of Interest Statement: The authors declare that the research was conducted in the absence of any commercial or financial relationships that could be construed as a potential conflict of interest.

Copyright $\odot 2018$ Rebolledo-Jaramillo and Ziegler. This is an open-access article distributed under the terms of the Creative Commons Attribution License (CC BY). The use, distribution or reproduction in other forums is permitted, provided the original author(s) and the copyright owner(s) are credited and that the original publication in this journal is cited, in accordance with accepted academic practice. No use, distribution or reproduction is permitted which does not comply with these terms. 